\title{
Theoretical Predictions of Lactate and Hydrogen Ion Distributions in Tumours
}

\author{
Maymona Al-Husari ${ }^{1}$, Steven D. Webb ${ }^{2 *}$
}

1 Department of Mathematics and Statistics, University of Strathclyde, Glasgow, United Kingdom, 2 MRC Centre for Drug Safety Science, Department of Molecular and Clinical Pharmacology, Institute of Translational Medicine, The University of Liverpool, Liverpool, United Kingdom

\begin{abstract}
High levels of lactate and $\mathrm{H}^{+}$-ions play an important role in the invasive and metastatic cascade of some tumours. We develop a mathematical model of cellular $\mathrm{pH}$ regulation focusing on the activity of the $\mathrm{Na}^{+} / \mathrm{H}^{+}$exchanger (NHE) and the lactate $/ \mathrm{H}^{+}$symporter (MCT) to investigate the spatial correlations of extracellular lactate and $\mathrm{H}^{+}$-ions. We highlight a crucial role for blood vessel perfusion rates in determining the spatial correlation between these two cations. We also predict critical roles for blood lactate, the activity of the MCTs and NHEs on the direction of the cellular pH gradient in the tumour. We also incorporate experimentally determined heterogeneous distributions of the NHE and MCT transporters. We show that this can give rise to a higher intracellular $\mathrm{pH}$ and a lower intracellular lactate but does not affect the direction of the reversed cellular $\mathrm{pH}$ gradient or redistribution of protons away from the glycolytic source. On the other hand, including intercellular gap junction communication in our model can give rise to a reversed cellular pH gradient and can influence the levels of $\mathrm{pH}$.
\end{abstract}

Citation: Al-Husari M, Webb SD (2013) Theoretical Predictions of Lactate and Hydrogen lon Distributions in Tumours. PLoS ONE 8(8): e72020. doi:10.1371/ journal.pone.0072020

Editor: Grant Lythe, University of Leeds, United Kingdom

Received December 12, 2012; Accepted July 11, 2013; Published August 21, 2013

Copyright: (c) 2013 Al-Husari, Webb. This is an open-access article distributed under the terms of the Creative Commons Attribution License, which permits unrestricted use, distribution, and reproduction in any medium, provided the original author and source are credited.

Funding: The authors have no support or funding to report.

Competing Interests: The authors have declared that no competing interests exist.

*E-mail: steven.webb@liverpool.ac.uk

\section{Introduction}

The microenvironment of tumours has been shown to trigger various signals which promote invasion $[1,2]$ and reduce tumour response to therapies [3,4]. An altered $\mathrm{pH}$ homoeostasis is increasingly becoming a distinct feature of some cancer cells [5]. While the intracellular $\mathrm{pH}\left(\mathrm{pH}_{\mathrm{i}}\right)$ in normal differentiated cells is generally $\sim 7.2$ and is less alkaline than the extracellular $\mathrm{pH}$ $\left(\mathrm{pH}_{e} \sim 7.4\right)$ [6], the intracellular $\mathrm{pH}$ of some malignant tumour cells can be greater than 7.4 and is found to be more alkaline than the extracellular $\mathrm{pH}\left(\mathrm{pH}_{e} \sim 6.5-7.1\right)[7,8]$. This gives rise to a reversed cellular $\mathrm{pH}$ gradient $\left(\mathrm{pH}_{i}>\mathrm{pH}_{e}\right)-$ also known as a negative cellular $\mathrm{pH}$ gradient $\left(\mathrm{pH}_{e}-\mathrm{pH}_{i}<0\right)-$ in these tumours which is thought to confer a survival advantage to the tumour over normal tissue $[9,10]$. An acidic $\mathrm{pH}_{e}$ has been shown to enhance the invasive behaviour of tumour cells $[1,11]$ and render them resistant to some chemotherapeutics $[12,13]$. On the other hand, an elevated $\mathrm{pH}_{i}$ has shown to have permissive effects on proliferation $[14,15]$, the evasion of apoptosis $[16,17]$ and is necessary for directed cell migration [18].

More than 80 years ago, Warburg [19] observed that tumour cells exhibit an altered metabolism, marked by increased glucose uptake and elevated glycolysis. In the absence of oxygen, pyruvate is converted into two molecules of lactic acid which dissociates rapidly into lactate and $\mathrm{H}^{+}$ions [20]. Warburg's pioneering work also showed that even in the presence of an ample supply of oxygen, tumour cells still undergo anaerobic glycolysis [19]. This type of energy metabolism is inefficient compared to aerobic metabolism and, for a vastly growing tumour to maintain sufficient production of ATP, the tumour cells must up-regulate their glycolytic pathway. As a result, more lactic acid is produced and the tumour can become very acidic [19]. In fact, tumours were initially thought to have an acidic intracellular $\mathrm{pH}\left(\mathrm{pH}_{i}\right)$. But, the invention of non-invasive measurements of $\mathrm{pH}_{i}$ by magnetic resonance spectroscopy (MRS) has shown that tumour $\mathrm{pH}_{i}$ can actually be alkaline [21].

The metabolically produced hydrogen ions must be extruded to ensure a physiological $\mathrm{pH}_{i}$ and maintain cell viability. This is because many cellular processes such as those associated with metabolism [22], the cell cycle [23,24] and cell proliferation $[25,26]$ are all pH sensitive. Furthermore, most mammalian cells will not proliferate at a $\mathrm{pH}$ less than 6.6 [25]. Cells, therefore, have evolved several short and long term mechanisms to maintain their $\mathrm{pH}_{i}$ within the normal physiological range $(\mathrm{pH} 7.2-7.4)$. Short term homoeostasis, for example, involves a rapid defence mechanism that minimises changes in $\mathrm{pH}$ as a result of acid or alkali load [25]. This includes physicochemical buffering, $\mathrm{H}^{+}-$ consuming metabolic buffering and organelle sequestration or release of hydrogen ions [25].

In addition, cells employ another strategy to maintain their $\mathrm{pH}$ through several membrane-based transport systems. The universal membrane protein, $\mathrm{Na}^{+} / \mathrm{H}^{+}$antiporter exports one $\mathrm{H}^{+}$ion outside the cell in return of one $\mathrm{Na}^{+}$ion [27]. This antiporter plays an essential physiological role in the regulation of cytoplasmic $\mathrm{pH}$, and a change in its activity can have a drastic effect on cell metabolism and viability [27]. The $\mathrm{Na}^{+} / \mathrm{H}^{+}$antiporter is freely reversible depending on both the cellular $\mathrm{Na}^{+}$and $\mathrm{H}^{+}$gradients. However, most mammalian cells maintain an inward cellular $\mathrm{Na}^{+}$ gradient which stimulates $\mathrm{H}^{+}$ions efflux. This process is tightly mediated by $\mathrm{pH}$ and the antiporter's activity changes by more 


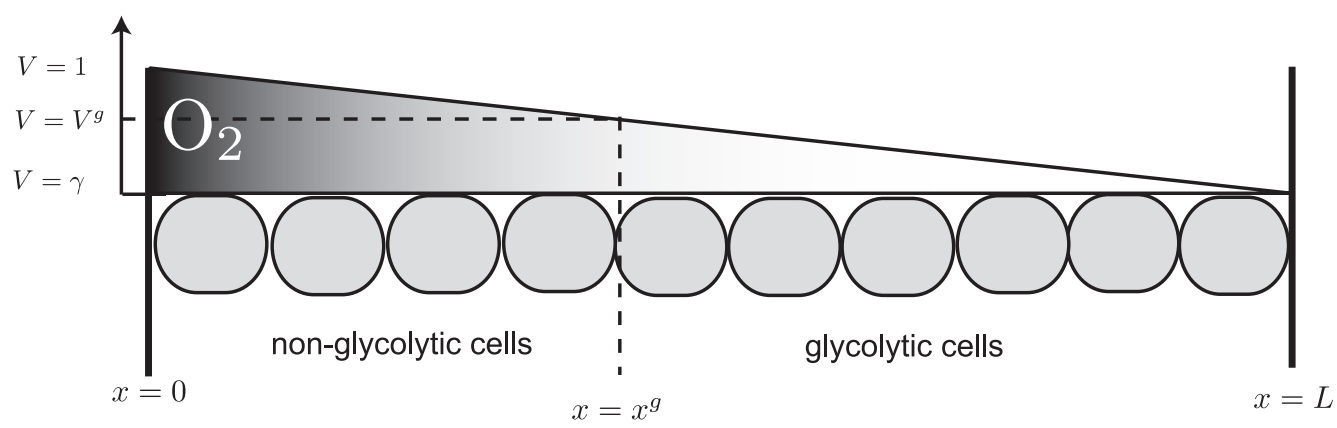

Figure 1. A schematic representation of the gradient of oxygen and the corresponding distribution of glycolytic $\left(V<V^{g}\right)$ and nonglycolytic cells $\left(V \geq V^{g}\right)$ in the model (1)-(4). $x=0$ denotes the location of the blood vessel. doi:10.1371/journal.pone.0072020.g001

than three orders of magnitude between $\mathrm{pH} 7$ and 8 (recall that $\left.\mathrm{pH}=-\log \left[\mathrm{H}^{+}\right]\right)$and is totally down-regulated below $\mathrm{pH} 6.5$ [27].

A key $\mathrm{pH}$ transmembrane exchanger is the lactate $/ \mathrm{H}^{+}$ symporter (also known as MCT-Monocarboxylate Transporter) [28]. This symporter works by transporting lactate and hydrogen ions together in the same direction. Depending on the cellular gradient of each ion, this process is freely reversible with equilibrium being attained when $\left[\right.$ lactate $\left._{i}\right] /\left[\right.$ lactate $\left._{e}\right]=\left[\mathrm{H}_{e}^{+}\right] /$ $\left[\mathrm{H}_{i}^{+}\right]$. There is a growing evidence suggesting that elevated tissue lactate levels are associated with a high risk of metastasis [28,29] and a reduced response to radiotherapy [30]. Moreover, reports by Cardone et al. [31] claim that the lactate $/ \mathrm{H}^{+}$symporter and the $\mathrm{Na}^{+} / \mathrm{H}^{+}$antiporter cause tumour acidity which in turn stimulates metastasis.

The contributions of mathematical modelling to the understanding of tumour growth and development dates back at least 60 years. Models mainly explore particular aspects of tumour growth and dynamics such as immunotherapy (e.g. see [32]), angiogenesis (e.g. see [33]) and invasion (e.g. see [34,35]). However, there are only relatively few mathematical models that consider tumour acidity. Amongst these are the work of [35-39]. Gatenby \& Gawlinski [36] derive an acid-mediated tumour invasion model which provides a simple mechanism linking altered glucose metabolism with the ability of tumour cells to form invasive cancers. The modelling of Webb et al. [38,39] includes descriptions of intracellular and extracellular $\mathrm{pH}$ and their effects on invasion. However, in this work the various cell-membrane transporters are represented in a simplified fashion. Moreover, they do not include lactate as a variable, but instead include the lactate $/ \mathrm{H}^{+}$symporter as a function depending wholly on extracellular $\mathrm{H}^{+}$and the degree of functioning vasculature. The role of sequestration of $\mathrm{H}^{+}$-ions into lysosomes is also considered in [39]. The modelling of Neville et al. [37] considers the evolution of intracellular and extracellular glucose as well as hydrogen ions.

Recently, we developed an ordinary differential equation (ODE) model for $\mathrm{pH}$ regulation that explicitly focuses on the interplay between $\mathrm{H}^{+}$-ions and lactate [40]. Analysis of this model showed that a reversed cellular $\mathrm{pH}$ gradient is attainable under aerobic conditions when the MCT activity is increased and other sources of $\mathrm{H}^{+}$-ions decreased-but we find the $\mathrm{pH}$ conditions predicted are too alkaline to be viable and therefore is unrealistic. To increase the biological realism of this earlier work we extend the model in this study to include spatial heterogeneity of lactate and $\mathrm{H}^{+}$-ions. In so doing, we also examine the findings of Provent et al. [41] that predict, in some cases, the spatial concentrations of extracellular lactate and extracellular hydrogen ions are often uncorrelated. We begin this study by investigating the conditions under which this phenomenon is observed. It is suggested that this is because protons, which are exported outside cells along with lactate in hypoxic regions, re-enter the cells indirectly via the $\mathrm{HCO}_{3}^{-} / \mathrm{Cl}$ exchanger or simply leak back into the cell and then are transported cell-to-cell via gap junctions to make protons available for the NHE exchanger [41]. Another study by Grillon et al. [42] reports that the distribution of NHEs and MCTs in rat brain gliomas are heterogeneous-the relative intensity of NHE1 (isoform 1) peaks at an average distance of $0.33 \pm 0.027 \mathrm{~mm}$ from the edge of the tumour and expression of the MCT1 (which can transport lactate and $\mathrm{H}^{+}$either out of or into cells [43]) peaks further into the glioma (1.05 $\pm 0.14 \mathrm{~mm}$ from the edge of the tumour). We also incorporate these findings into the model and examine their effect on the cellular $\mathrm{pH}$ gradient. We then finally investigate the effect of $\mathrm{H}^{+}$-ion intercellular gap junctions on the cellular $\mathrm{pH}$ gradient reversal and the spatial distribution of extracellular lactate and $\mathrm{H}^{+}$ions.

\section{Methods}

We model a 2-D slice through a three-dimensional tumour mass, but we average the dependent variables in the plane perpendicular to the edge of the tumour to reduce the problem to one that is one-dimensional. Our modelling domain is between the blood vessel and $2 \mathrm{~mm}$ into the tumour mass. We restrict ourselves to this because we have corresponding experimental data for this size of section. We assume that the tumour extends beyond $2 \mathrm{~mm}$ and we assign appropriate perfusions of the chemical constituents into this extended region. The cells have two compartmentsintracellular and extracellular-and we focus on the regulation of lactate and $\mathrm{H}^{+}$between these two compartments. The extracellular space in our model represents the small interstitial spaces between the tumour cells. We assume that the volumes of these intra- and extracellular compartments are comparable and we take them to be equal in our analysis. Our model considers the spatial and temporal evolution of $\mathrm{H}^{+}$which we denote by $H_{\sigma}, \sigma \in\{I, E\}$ where $I, E$ denotes intracellular and extracellular concentrations, and lactate $\left(L_{\sigma}\right)$ where $\sigma \in\{I, E\}$. We define the cellular $\mathrm{pH}$ gradient to be $\mathrm{pHpH}_{e}-\mathrm{pH}_{i}$ and the cellular lactate gradient to be $L_{E}-L_{I}$. For simplicity, we assume a one-dimensional Cartesian geometry, namely $0 \leq x \leq L$, where $L$ denotes the distance away from the blood vessel which is located at $x=0$. Rather than including the complexity of an additional equation for oxygen, we simply assume a linear decreasing concentration of oxygen (denoted by $V$ ) from the blood vessel located at $x=0$, namely $V=1+(2 \gamma-1) x / L$, where $2 \gamma=\in[0,1)$ (see Fig. 1 for a schematic). Note that similar to [40] we have rescaled oxygen to be one at the blood vessel. With appropriate choices of $2 \gamma$, we can either simulate a tumour which is completely well-oxygenated (e.g. 
Table 1. Dimensionless parameter estimates used in the one-dimensional spatial model in (5)-(8).

\begin{tabular}{|c|c|c|c|c|}
\hline Description & Symbol & Definition & Value & Ref. \\
\hline$x=0$ Vessel permeability to $\mathrm{H}^{+}$at & $\tilde{\rho}_{H l}$ & $\rho_{H I} / \sqrt{\alpha_{4} D_{H}}$ & $4.4 \times 10^{-2} / \sqrt{\alpha_{4}}$ & Estimate \\
\hline$x=0$ Vessel permeability to lactate at & $\tilde{\rho}_{L l}$ & $\rho_{L r} \sqrt{D_{H}} / D_{L} \sqrt{\alpha_{4}}$ & $4.4 \times 10^{-2} / \sqrt{\alpha_{4}}$ & [61] \\
\hline$x=L T$ issue permeability to lactate at & $\tilde{\rho}_{L r}$ & $\rho_{L r} \sqrt{D_{H}} / D_{L} \sqrt{\alpha_{4}}$ & $4.4 \times 10^{-2} / \sqrt{\alpha_{4}}$ & Estimate \\
\hline Normal $\mathrm{H}^{+}$concentration in blood & $\tilde{H}_{\infty l}$ & $H_{\infty} / b$ & $0.35-0.45$ & [12] \\
\hline$x=0$ Lactate concentration in blood at & $\tilde{L}_{\infty l}$ & $\alpha_{4} L_{\infty} / d_{4}$ & $0.35-0.71$ & [63] \\
\hline$x=L$ Lactate concentration in the tissue at & $\tilde{L}_{\infty r}$ & $\alpha_{4} L_{\infty} / d_{4}$ & 1.42 & {$[62]$} \\
\hline$x=L \mathrm{H}^{+}$-ions concentration in the tissue at & $\tilde{H}_{\infty}$ & $H_{\infty r} / b$ & 3.16 & PC \\
\hline Diffusion co-efficient fraction & $\tilde{D}_{L}$ & $D_{L} / D_{H}$ & 0.81 & {$[59,60]$} \\
\hline Tissue size & $\tilde{L}$ & $L \sqrt{\alpha_{4} / D_{H}}$ & 0.02 & PC \\
\hline Rate of H-leakage inside the cell & $\tilde{l}_{H}$ & $l_{H} / \alpha_{4}$ & $1.7174 \times 10^{-2}$ & [47] \\
\hline Rate of NHE activity & $\tilde{f}_{1}$ & $f_{1} / \alpha_{4}$ & $1.7174 \times 10^{4}$ & Estimate \\
\hline Rate of MCT activity & $\tilde{k}_{3}$ & $k_{3} b / \alpha_{4}$ & 5.4316 & Estimate \\
\hline Background production of intracellular $\mathrm{H}^{+}$ & $\tilde{d}_{1}$ & $d_{1} / b \alpha_{4}$ & $7.9996 \times 10^{3}$ & Estimate \\
\hline Rate of glycolysis & $\tilde{\Phi}_{G}$ & $\Phi_{G} / b d_{4}$ & 0.2823 & [51] \\
\hline Scaling factor & $\psi$ & $d_{4} / b \alpha_{4}$ & $1.4 \times 10^{4}$ & Estimate \\
\hline Initial intracellular $\mathrm{H}^{+}$concentration & $\tilde{H}_{I}^{0}$ & $H_{I}^{0} / b$ & 0.63 & [6] \\
\hline Initial extracellular $\mathrm{H}^{+}$concentration & $\tilde{H}_{E}^{0}$ & $H_{E}^{0} / b$ & 0.63 & [6] \\
\hline Initial intracellular lactate concentration & $\tilde{L}_{I}^{0}$ & $\alpha_{4} L_{I}^{0} / d_{4}$ & 1 & [63] \\
\hline Initial extracellular lactate concentration & $\tilde{L}_{E}^{0}$ & $\alpha_{4} L_{E}^{0} / d_{4}$ & 1 & [63] \\
\hline
\end{tabular}

$\mathrm{PC}=$ personal communications with Jonathan Coles, Institute of Photonics, University of Strathclyde.

doi:10.1371/journal.pone.0072020.t001

if $2 \gamma=1$ ) or a tumour that is hypoxic for $x^{g}<x \leq L$ and aerobic for $0 \leq x \leq x^{g}$, where $x=x^{g}$ is the point beyond which glycolysis prevails.

Our model has the form

$$
\begin{aligned}
& \frac{d H_{I}}{d t}=\underbrace{\frac{2 \Phi_{G} \mathrm{~J}\left(x^{g}-x\right)}{H_{I}+b}}_{\mathrm{H}^{+}}+\underbrace{d_{1}}_{\text {production from glycolysis }}+\phi, \\
& \frac{d L_{I}}{d t}=\underbrace{\frac{2 \Phi_{G} \mathrm{~J}\left(x^{g}-x\right)}{H_{I}+b}}_{\mathrm{H}^{+} \text {production from gources of } \mathrm{H}^{+}}+\underbrace{d_{4}}_{\text {other sources of lactate }}-\underbrace{\alpha_{4} L_{I}}_{\text {lactatede gradation }}-\theta,(2)
\end{aligned}
$$

$$
\begin{gathered}
\frac{\partial H_{E}}{\partial t}=\underbrace{D_{H} \frac{\partial^{2} H_{E}}{\partial x^{2}}}_{\mathrm{H}^{+} \text {diffusion }}-\phi, \\
\frac{\partial L_{E}}{\partial t}=\underbrace{D_{L} \frac{\partial^{2} L_{E}}{\partial x^{2}}}_{\text {lactate diffusion }}+\theta,
\end{gathered}
$$

where,

$$
\begin{aligned}
& \theta=\underbrace{k_{3}\left(H_{I} L_{I}-H_{E} L_{E}\right)}_{\text {MCT symporter }}, \\
& \phi=\underbrace{l_{H}\left(H_{E}-H_{I}\right)}_{\mathrm{H}^{+} \text {leakage }}-\underbrace{f_{1} \mathrm{~J}\left(H_{I}-H_{E}\right)\left(H_{I}-H_{E}\right)}_{\mathrm{Na}^{+} / \mathrm{H}^{+} \text {antiporter }}-\underbrace{k_{3}\left(H_{I} L_{I}-H_{E} L_{E}\right)}_{\text {MCT symporter }},
\end{aligned}
$$

and $\mathbf{J}(\cdot)$ is a Heaviside function, which is a binary function, being one if the dependent variable is positive and zero otherwise.

We first clarify each of the model expressions in turn. Note that there are more detailed models for cellular ion transport based on the Goldman-Hodgkin-Katz equations - which play an important role in models for cellular electrical activity. However, we adopt a simple phenomenological approach based on experimental observations of transport rates as functions of ion concentration. For instance, the $\mathrm{Na}^{+} / \mathrm{H}^{+}$transporter term is taken to be linear and uni-directional based on experimental observations by Boyer \& Tannock [44]. This type of modelling approach has been successfully adopted previously by, for example, Webb et al. [38,39], Al-Husari \& Webb [40], Neville [37], Vinnakota \& Beard [45], Aubert \& Costalat [46].

1. $l_{H}\left(H_{E}-H_{I}\right)$

This term describes the rate at which $\mathrm{H}^{+}$ions enter the cell due to the internally negative potential of the cell membrane. It is assumed to be directly proportional to the difference in the 


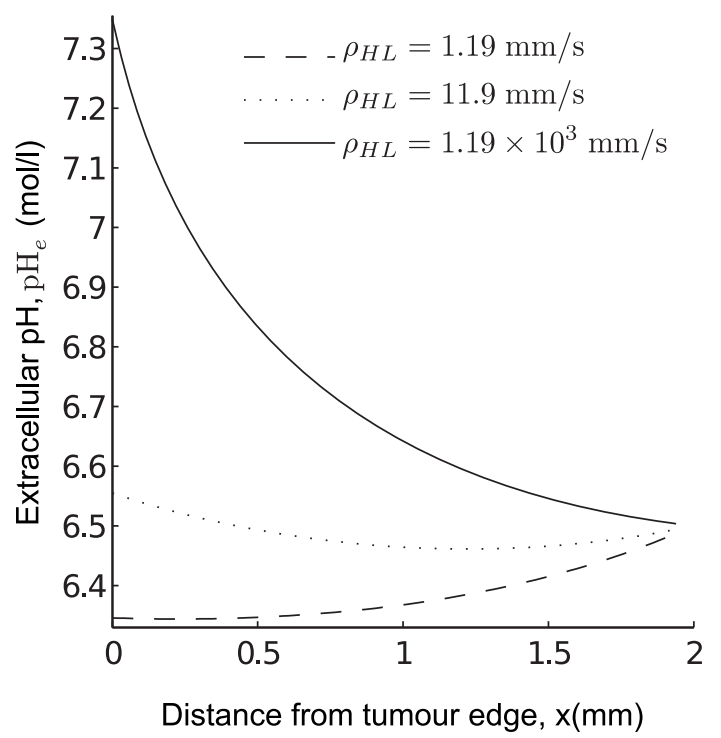

Figure 2. Effect of varying the rate of $\mathrm{H}^{+}$leakage into the blood vessel $\left(\rho_{H l}\right)$ on $\mathbf{p H}_{e}$. We show how $\mathrm{pH}_{e}$ near the blood vessel varies as the rate of $\mathrm{H}^{+}$leakage into the blood vessel varies. Parameter values are as in Table 1 and with $\rho_{L r}=0.44, L_{\infty l}=0.5, L_{\infty r}=1.42, H_{\infty l}=0.398$. The prescribed model is simulated until the steady state solution is reached, starting from the initial conditions: $H_{I}^{0}=0.63, H_{E}^{0}=0.63$, $L_{I}^{0}=1$ and $L_{E}^{0}=1$. We determine whether the steady state solution is reached by considering the solution at time step, $i$, and time step, $i+1$. If the absolute difference in solution is less than some $\varepsilon$ (we choose to be $\left.10^{-6}\right)$, then the model stops running at the $i^{\text {th }}$ step. With this value of $\varepsilon$, the metabolites reach a steady state at $t=6$. doi:10.1371/journal.pone.0072020.g002

hydrogen ion concentration across the cell membrane. The permeability of the cell membrane to $\mathrm{H}^{+}$ions is approximately $10^{-14} \mathrm{~m} / \mathrm{s}$ [47]. Dividing this by the typical width of the bilayer $(\sim 10 \mathrm{~nm})[47]$ gives an estimation for $l_{H}$ as $10^{-6} \mathrm{~s}^{-1}$.

2. $f_{1} \mathrm{~J}\left(H_{I}-H_{E}\right)\left(H_{I}-H_{E}\right)$

This term models the rate at which $\mathrm{H}^{+}$ions are exported outside the cell via the $\mathrm{Na}^{+} / \mathrm{H}^{+}$exchanger (NHE for short) and we assume that the rate of $\mathrm{H}^{+}$efflux is directly proportional to the cellular $\mathrm{H}^{+}$ gradient across the cell membrane, i.e. $H_{I}-H_{E}$. This is based on experiments carried out by Boyer \& Tannock [44] that report that the rate of $\mathrm{H}^{+}$efflux is linearly proportional to the transmembrane $\mathrm{H}^{+}$gradient $\left(H_{I}-H_{E}\right)$ in MGHUl human bladder carcinoma cells and unidirectional for the $\mathrm{pH}$ ranges considered. The function $\mathrm{J}$ is used to prevent any $\mathrm{H}^{+}$influx which is typically not observed via this transporter. The constant $f_{1}$ is a parameter which denotes the rate of $\mathrm{H}^{+}$flux, and carries the units of $\mathrm{s}^{-1}$.

3. $k_{3}\left(H_{I} L_{I}-H_{E} L_{E}\right)$

This term represents the rate at which hydrogen ions are extruded along with lactate ions. These ions are transported via a Monocarboxylate Transporter (MCT) located at the plasma membrane. A study by McDermott et al. [48] showed that lactate transport is saturable with respect to increasing concentrations of lactate and hydrogen ions, but for simplicity we assume that this transporter is acting in the linear regime-a full derivation of this term is given in [40]. The constant $k_{3}\left(\mathrm{~mol}^{-1} / \mathrm{l}^{-1} / \mathrm{s}\right)$ describes the rate at which hydrogen ions and lactate are exported or imported.

4. $d_{1}$

This term implicitly accounts for sources of $\mathrm{H}^{+}$ions in the cell other than via glycolysis. For example, this could include the catalysed hydration of $\mathrm{CO}_{2}$ into $\mathrm{H}^{+}$and $\mathrm{HCO}_{3}^{-}$by Carbonic Anhydrase [49]. This buffering parameter is a leading order representation of a process that is short term, in relation to ion pumps which act over the long term to reduce acidosis, and hence we assume it to be quasi-steady and taken to be constant.

5. $2 \Phi_{G} \mathrm{~J}\left(x^{g}-x\right) /\left(H_{I}+b\right)$

This term models the net production of $\mathrm{H}^{+}$ions via the process of glycolysis. Glycolysis is a metabolic pathway involving a complex chain of chemical reactions that produces energy rich molecules (ATP) [47]. Studies by Kaminkas [50] showed that glucose transport and consumption in cultured Ehrlich ascitestumour cells are $\mathrm{pH}$ dependent. Decreasing $\mathrm{pH}_{i}$ is found to decrease the rate of glucose consumption [25,51]. In particular, the key glycolytic enzyme phosphofructokinase is found to be critically pH sensitive [20]. This dependency of intracellular $\mathrm{H}^{+}$is also included by Neville [37] in her model for tumour glycolysis. In our model, we assume a threshold degree of vasculature $\left(V^{g}\right)$, above which a cell will undergo aerobic metabolism, and below which anaerobic glycolysis will prevail. We define how vasculature is included in the model below. In the presence of an oxygen supply $\left(V>V^{g}\right)$, there is no net production of $\mathrm{H}^{+}$ions as aerobic metabolism is shown not to produce any net $\mathrm{H}^{+}$-ions [52]. However, in low oxygen concentrations $\left(V<V^{g}\right)$, two $\mathrm{H}^{+}$-ions are produced from the dissociation of lactic acid [52]. We assume glucose to be plentiful, which is reasonable given the observed large diffusion distance of glucose [53]. The constant $\Phi_{G} / b$ represents the maximal rate of glycolysis. We use the results of [51] for EMT6/R0 mouse mammary tumour cells to estimate $\Phi_{G}$ and $b$. In this study, it is noted that glucose is consumed at a rate of $2 \times 10^{-14} \mathrm{~g} / \mathrm{cell} / \mathrm{s}$ at a $\mathrm{pH}$ of 7.2 . One mol of glucose has a relative molecular mass of $180 \mathrm{~g}$ and one cell has a volume of roughly $10^{-15} \mathrm{~m}^{3}$ [54]. This corresponds to a glucose consumption rate of $1.1 \times 10^{-4} \mathrm{~mol} / \mathrm{m}^{3} / \mathrm{s}$. If we choose $b=10^{-7} \mathrm{~mol} / 1$ then $\Phi_{G}=10^{-14}(\mathrm{~mol} / \mathrm{l})^{2} / \mathrm{s}$. We assume that $b$ does not change between normal and tumour cells. However, tumours are known to have a higher glycolytic rate than normal cells and we represent this excess by an increase in $\Phi_{G}$.

\section{6. $d_{4}$}

Even under aerobic conditions, there is evidence to suggest that there is some degree of lactate production [55]. Lactate is known to be only produced via the breakdown of pyruvate which is made from either glucose or some amino acids [56]. Therefore, since our model assumes no production of lactate from glucose under aerobic conditions, $d_{4}$ may still account for a minor production from glucose. On the other hand, under anaerobic conditions, $d_{4}$ may account for lactate production from some amino acids. In non-stressed or non-shocked animals, significant lactate is produced to maintain a concentration of $0.7 \mathrm{mM}$ [57]. It has been estimated [57] that lactate is produced in the resting human at the following rates $(\mathrm{mM} / \mathrm{h} / \mathrm{kg})$ : skeletal mass, 3.13; brain, 0.14 ; red cell mass, 0.18; and 0.11 for blood elements, renal medulla, intestinal mucosa and skin. Total lactate production in a $70-\mathrm{kg}$ male is approximately $1,300 \mathrm{mM} /$ day [57].

7. $\alpha_{4} L_{I}$

This term implicitly describes the rate at which lactate is converted back to pyruvate. That is, if we assume a linear conversion from pyruvate to acetyl-coA and steady state efflux conditions then one can estimate a linear relationship between pyruvate and lactate concentrations and then obtain a linear loss term for lactate, namely $\alpha_{4} L_{I} i$. A similar approach has been adopted in Bertuzzi et al. [58]. We currently have no available data to approximate this value and so we vary it in our analysis.

The current model differs from our recent work in [40] via the added diffusion terms of extracellular $\mathrm{H}^{+}$-ions and lactate, with diffusion coefficients $D_{H}$ and $D_{L}$ respectively. Also, here the boundary conditions at $x=0$ replace the terms, $R_{\sigma}(V), \sigma=1$ and 
A
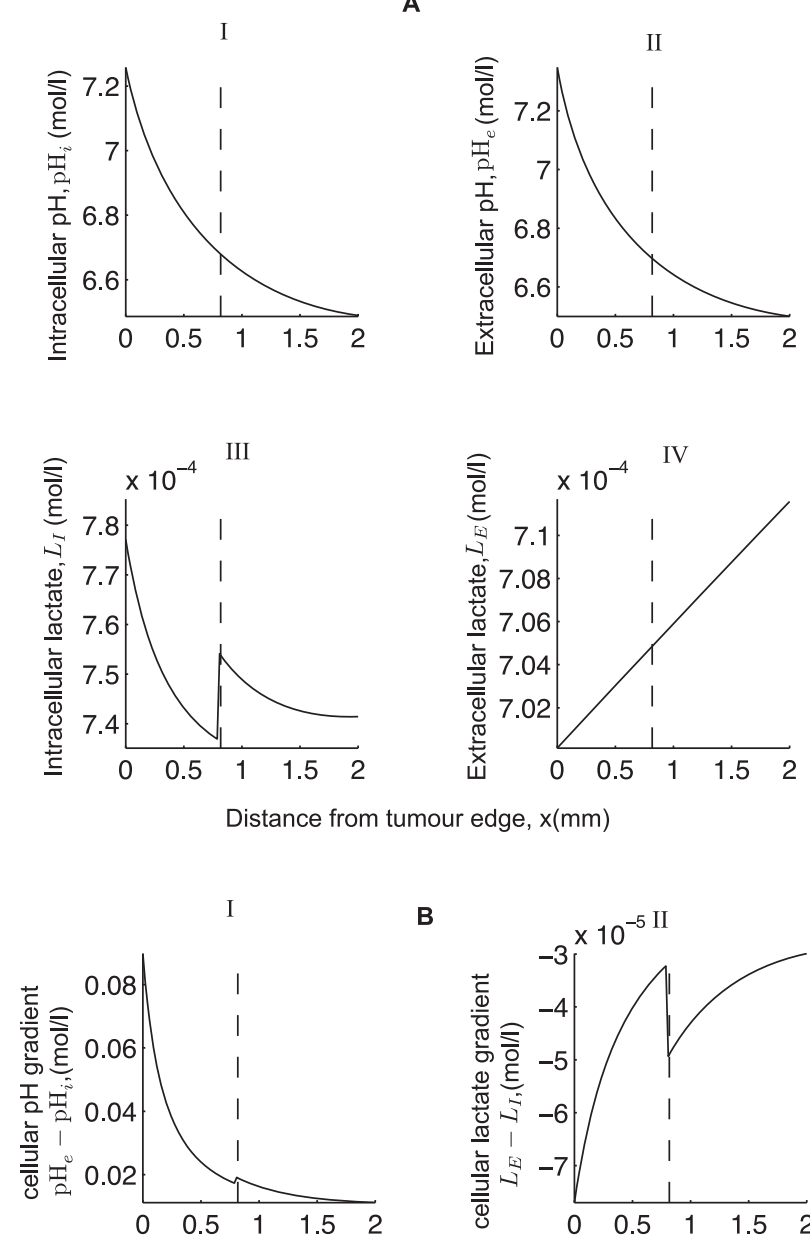

B

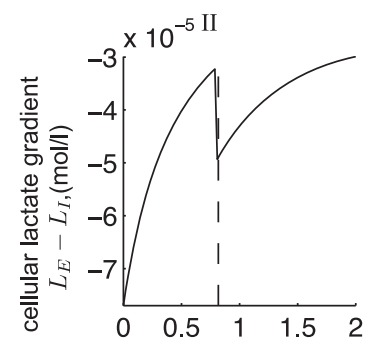

III

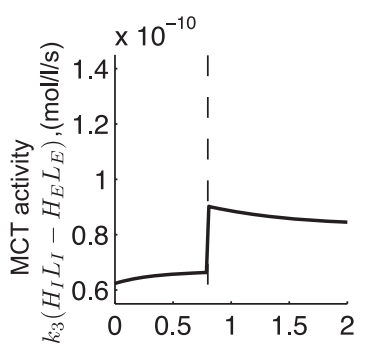

Distance from tumour edge, $x(\mathrm{~mm})$

Figure 3. Numerical solution of the system (5)-(8) showing a correlation between $\mathbf{p H}_{e}$ and $\boldsymbol{L}_{E}$. The vertical dashed lines denote $x=x^{g}$, where here $x^{g}=(42 \gamma+6) / 10$, with $2 \gamma$ chosen to be 0.1 throughout the simulations in this study. (A) A spatial correlation exists between extracellular lactate levels and $\mathrm{pH}_{e}$ (e.g. compare (A) II and (A) IV). (B) I shows the $\mathrm{pH}$ gradient, (B) II the lactate gradient, (B) III the MCT activity and (B) IV the NHE activity. Parameter values are as in Table 1 with $\rho_{H l}=4.4 \times 10^{3}, \rho_{L l}=4.4 \times 10^{3}, \rho_{L r}=0.44, L_{\infty l}=0.5, L_{\infty r}=1.42$, $H_{\infty l}=0.398$. The prescribed model is simulated until the steady state solution is reached, starting from the initial conditions: $H_{I}^{0}=0.63$, $H_{E}^{0}=0.63, L_{I}^{0}=1$ and $L_{E}^{0}=1$. We determine whether the steady state solution has been reached as in Figure 2 . doi:10.1371/journal.pone.0072020.g003
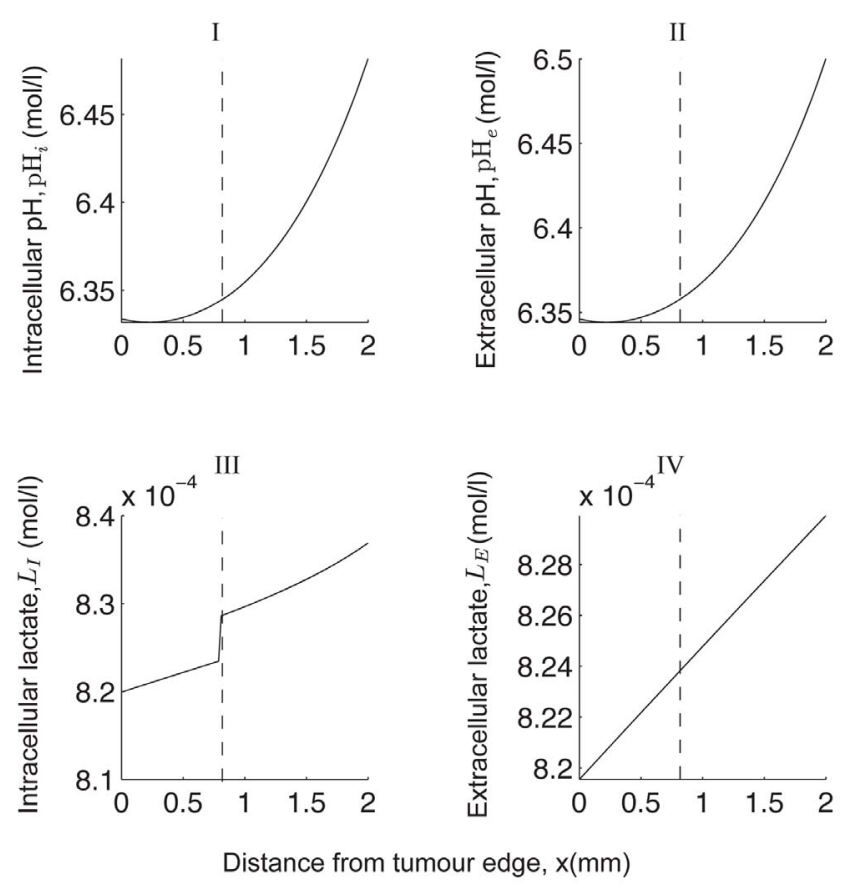

Figure 4. Numerical solution to equations (5)-(8) showing a lack of spatial correlation between extracellular $\mathrm{H}^{+}$and $L_{E}$. This is obtained using parameter values as in Fig. 3 but with a reduced rate of leakage of $\mathrm{H}^{+}$-ions and lactate into the blood stream (i.e. $\left.\rho_{H l}, \rho_{L l}=4.4\right)$, compare II with IV. The model is simulated until the steady state solution is reached, starting from the initial conditions: $H_{I}^{0}=0.63, H_{E}^{0}=0.63, L_{I}^{0}=1$ and $L_{E}^{0}=1$. We determine whether the steady state solution is reached the same way as stated in the caption for Fig. 2. Note that the spatial profiles for the cellular $\mathrm{pH}$ gradients, MCT and NHE activities are qualitatively similar to the plots for $\mathrm{pH}_{i}, \mathrm{~L}_{\text {, }}$ and $L_{E}$, respectively, and so we omit them for brevity. doi:10.1371/journal.pone.0072020.g004

2, used in [40] for the vascular removal of extracellular $\mathrm{H}^{+}$-ions and lactate, respectively. We assume that glucose supply is plentiful $\forall x \in[0, L]$. We impose boundary conditions to represent a tumour with a well-perfused blood vessel (on the left side of the tissue, $x=0$ ) which supplies the tumour with oxygen and removes $\mathrm{H}^{+} \mathrm{Z}$-ions and lactate. That is.

$$
\begin{aligned}
& \text { At } \quad x=0: \quad D_{H} \frac{\partial H_{E}}{\partial x}(0, t)=\rho_{H l}\left(H_{E}(0, t)-H_{\infty l}\right), \\
& D_{L} \frac{\partial L_{E}}{\partial x}(0, t)=\rho_{L l}\left(L_{E}(0, t)-L_{\infty l}\right)
\end{aligned}
$$

where $H_{\infty l}$ and $L_{\infty l}$ are, respectively, the concentrations of hydrogen ions and lactate inside the blood vessel at $x=0$. Their rate of leakage into or out of the blood vessel at $x=0$ is regulated by the parameters $\rho_{H l}$ and $\rho_{L l}$ respectively. A similar notation is used for lactate at the right hand side boundary condition, but with $L_{\infty r}$ denoting estimated tissue lactate levels:

$$
\text { At } \quad x=L: \quad H_{E}(L, t)=H_{\infty r},
$$




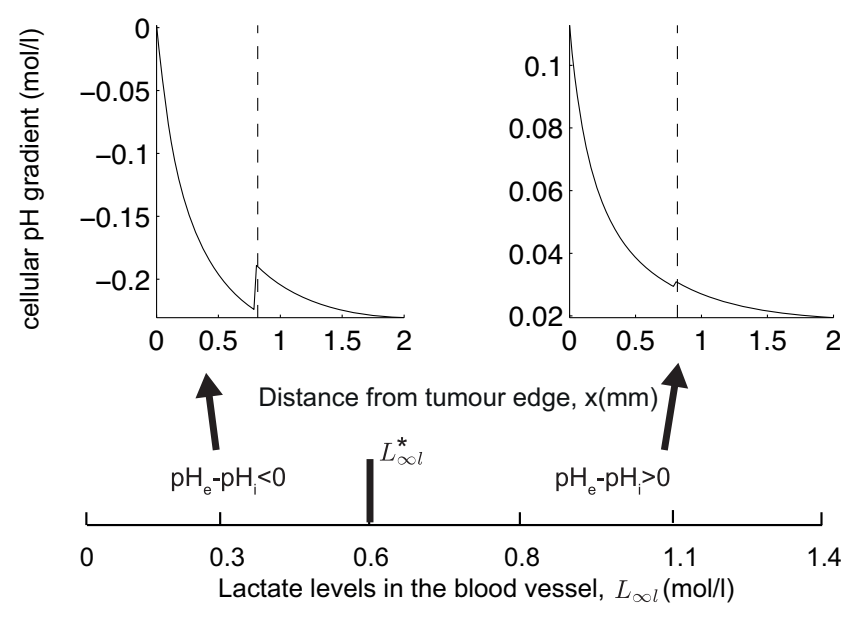

Figure 5. Effect of varying blood lactate levels $\left(L_{\infty}\right)$ on the cellular $\mathbf{p H}$ gradient $\mathbf{p} \mathbf{H}_{e}-\mathbf{p} \mathbf{H}_{\boldsymbol{i}}$. For $L_{\infty}>L_{\infty}^{*}$ all the cells exhibit a negative cellular $\mathrm{pH}$ gradient; for $L_{\infty l}>L_{\infty}^{*}$ all cells have a positive cellular $\mathrm{pH}$ gradient. Shown above the horizontal panel are typical spatial profiles of the cellular $\mathrm{pH}$ gradient in the two cases $L_{\infty} l<L_{\infty}^{*}$ and $L_{\infty l}>L_{\infty}^{*}$. For each set of chosen parameters, the model is simulated until the steady state solution is reached, starting from the initial conditions: $H_{I}^{0}=0.63, H_{E}^{0}=0.63, L_{I}^{0}=1$ and $L_{E}^{0}=1$. We determine whether the steady state solution is reached the same way as stated in the caption to Fig. 2. $L_{\infty}=1$ in each subplot and remaining parameters are the same as in the caption to Fig. 3. doi:10.1371/journal.pone.0072020.g005

$$
-D_{L} \frac{\partial L_{E}}{\partial x}(L, t)=\rho_{L r}\left(L_{E}(L, t)-L_{\infty r}\right)
$$

Based on an experimental observation, we take a fixed boundary condition at $x=L$ for the extracellular $\mathrm{H}^{+}$since findings show that at $L=2 \mathrm{~mm}$, the extracellular $\mathrm{pH}$ is known to be around 6.5 (Personal Communication with Jonathan Coles, Institute of Photonics, University of Strathclyde). Our rationale is that beyond $2 \mathrm{~mm}$ the environment is too hypoxic to allow sufficient cell metabolism and thus we expect the net production of lactate and $\mathrm{H}^{+}$to be low, therefore facilitating the inflow of these constituents from the high producing $0<x<2 \mathrm{~mm}$ tumour region. We cannot find appropriate values for the tumour tissue lactate at or beyond $2 \mathrm{~mm}$ and so we do not adopt the same boundary condition at $x=2 \mathrm{~mm}$ for lactate as we do for $\mathrm{pH}_{e}$. However, we take it to be of the same order as that of normal blood lactate but, ultimately, we find that the solutions are not very sensitive to the particular value chosen.

We denote the initial values by their normal concentration in the tissue, namely, $H_{I}(x, 0)=H_{I}^{0} \mathrm{~mol} / \mathrm{l}, H_{E}(x, 0)=H_{E}^{0} \mathrm{~mol} / \mathrm{l}$, $L_{I}(x, 0)=L_{I}^{0} \mathrm{~mol} / \mathrm{l}, L_{E}(x, 0)=L_{E}^{0} \mathrm{~mol} / \mathrm{l}$.

\section{Non-dimensionlisation}

To facilitate the numerical study of the model, we rescale the system using the following rescalings, where the tilde represents the rescaled space variable:
A Low tissue lactate

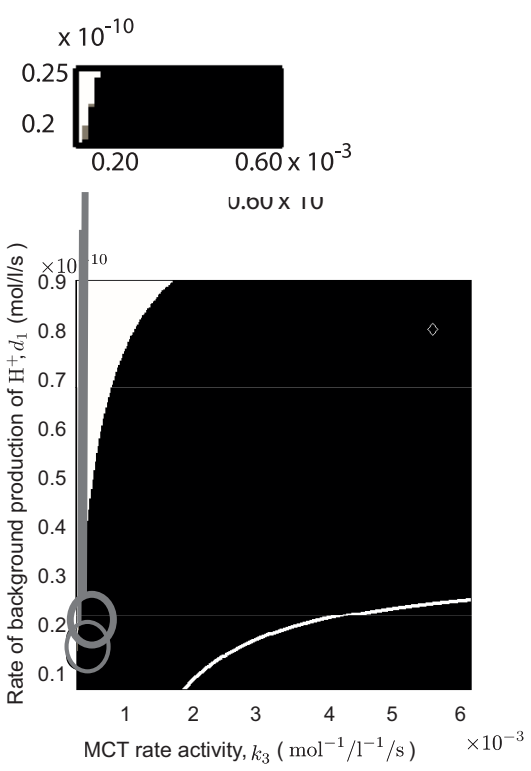

B High tissue lactate

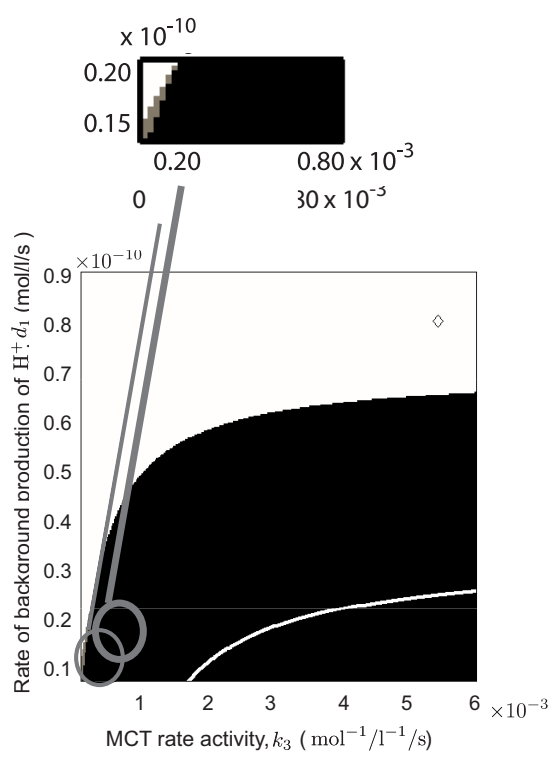

Figure 6. Effect of varying the MCT rate activity $\left(k_{3}\right)$ and the background production rate of $\mathbf{H}^{+}\left(d_{1}\right)$ on the cellular pH gradient in the cases of high and low tissue lactate $\left(L_{\infty}\right)$. In (A) low tissue lactate $\left(L_{\infty r}=0.3\right)$ and (B) high tissue lactate $\left(L_{\infty}=1.42\right)$. The remaining parameters are the same as in the caption to Fig. 3. For parameters in the black shaded region all cells have a negative $\mathrm{pH}$ gradient (i.e. $p H_{i}>p H_{e}$ ). In the white regions, $p H_{i}<p H_{e}$. We also superimpose the results from our well-mixed ODE model in [40] which shows that parameter values below the white curve yield a reversed cellular $\mathrm{pH}$ gradient and above the curve otherwise. The base case parameter set (see Table 1) is depicted in the figure by a "diamond". In (A) $L_{\infty l}=0.2$, in (B) $L_{\infty l}=0.5$. The grey shaed region in the inserts denote regions where a reversed pH gradient only occurs in the non-glycolytic cells (i.e. $V \geq V^{g}$ ).

doi:10.1371/journal.pone.0072020.g006 


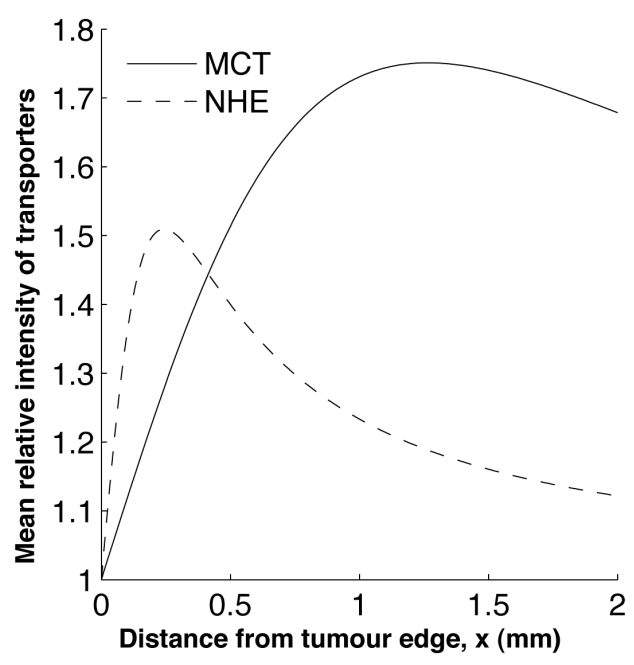

Figure 7. Spatial organisation of the NHE and the MCT in brain glioma as observed in [42]. Note that the average intensity of the transporters outside the tumour is set to one. doi:10.1371/journal.pone.0072020.g007

$$
\begin{gathered}
\tilde{x}=\sqrt{\alpha_{4} / D_{H}} x, \quad \tilde{H}_{I}=H_{I} / b, \quad \tilde{H}_{E}=H_{E} / b, \\
\tilde{L}_{I}=\alpha_{4} L_{I} / d_{4}, \quad \tilde{L}_{E}=\alpha_{4} L_{E} / d_{4}, \quad \tilde{t}=\alpha_{4} t .
\end{gathered}
$$

The dimensionless equations then read

$$
\begin{gathered}
\frac{d \tilde{H}_{I}}{d \tilde{t}}=\frac{2 \tilde{\Phi}_{G} \psi \mathrm{J}\left(x^{g}-x\right)}{\tilde{H}_{I}+1}+\tilde{d}_{1}+\tilde{\phi} \\
\frac{d \tilde{L}_{I}}{d \tilde{t}}=\frac{2 \tilde{\Phi}_{G} \mathrm{~J}\left(x^{g}-x\right)}{\tilde{H}_{I}+1}+1-\tilde{L}_{I}-\tilde{\theta} \\
\frac{\partial \tilde{H}_{E}}{\partial \tilde{t}}=\frac{\partial^{2} \tilde{H}_{E}}{\partial \tilde{x}^{2}}-\tilde{\phi} \\
\frac{\partial \tilde{L}_{E}}{\partial \tilde{t}}=\tilde{D}_{L} \frac{\partial^{2} \tilde{L}_{E}}{\partial \tilde{x}^{2}}+\tilde{\theta}
\end{gathered}
$$

See Table 1 for a list of how the dimensionless parameters are calculated and their estimated values.

\section{Results}

\section{Spatial Discretisation and Numerical Scheme}

We divide the spatial domain into $N$ uniformly spaced points with grid size, $\Delta x=L /(N-1)$. This allows the problem to be solved by the method of lines and gears using MATLAB's built-in ODE solver (ode15s) with four ODEs in time (for $H_{I}, H_{E}, L_{I}, L_{E}$ ) at each space point. The grid function $u\left(x_{j}, t\right), u \in\left\{H_{I}, H_{E}, L_{I}, L_{E}\right\}$, denotes an approximation of $u$ at $x_{j}$, where $1 \leq j \leq N$. For the diffusion terms of $H_{E}$ and $L_{E}$, we use a simple finite difference approximation using a second order central difference.

\section{Parameter Estimates}

From the literature, we are able to estimate some of the model parameters. We take the diffusion co-efficient of $\mathrm{H}^{+}$ions $\left(D_{H}\right)$ to be $1.08 \times 10^{-5} \mathrm{~cm}^{2} / \mathrm{s}$ [59] and that of lactate $\left(D_{L}\right)$ to be $8.8 \times 10^{-6} \mathrm{~cm}^{2} / \mathrm{s}$ [60]. We assume that cells near the blood vessel are well-oxygenated and that extracellular lactate and $\mathrm{H}^{+}$-ions leak in or out of the blood vessel at a much higher rate than extracellular lactate does into the tissue at $x=L$ due to the leakiness of the tumour vasculature. The vessel permeability to lactic acid $\left(\rho_{L l}\right)$ is taken to be $1.19 \times 10^{-4} \mathrm{~cm} / \mathrm{s}$ [61], for which the non-dimensional equivalence is $4.4 \times 10^{-2} / \sqrt{\alpha_{4}}$. With a lack of available data, we also assume that $\mathrm{H}^{+}$ions have the same vessel permeability as lactate. Also, because of the lack of available data on the rate of lactate decay $\left(\alpha_{4}\right)$, we vary this parameter in our study and note the effect on the overall model behaviour.

In general, normal blood lactate in unstressed patients is between $0.5-1.0 \times 10^{-3} \mathrm{~mol} / \mathrm{l}$, but for patients with critical illnesses, concentrations of more than $2.0 \times 10^{-3} \mathrm{~mol} / \mathrm{l}$ are sometimes found [62]. With this in mind, we estimate lactate levels inside the blood vessel at $x=0, L_{\infty}$, to be $0.5-$ $1.0 \times 10^{-3} \mathrm{~mol} / \mathrm{l}$ [63], and lactate $2 \mathrm{~mm}$ away from the blood vessel, $L_{\infty r}$, to be $2.0 \times 10^{-3} \mathrm{~mol} / \mathrm{l}$ [63]. From our parameter estimates in [40] we find that $d_{4} / \alpha_{4} \sim O\left(10^{-3}\right) \equiv 1.4 \times 10^{-3} \mathrm{~mol} /$ 1, which gives $\tilde{L}_{\infty l}=0.35-0.71$ and $\tilde{L}_{\infty r}=1.42$ (in dimensionless form). The normal blood $\mathrm{H}^{+}$concentration in unstressed patients is found to be in the range of 3.55-4.5 $\times 10^{-8} \mathrm{~mol} / \mathrm{l}$ [64] and we take this value to represent $H_{\infty} l$.

Almost fifty years following Warburg's pioneering work on tumour metabolism [19], extensive studies have concluded that glucose is a main energy source for malignant tumours $[65,66]$ and that $60 \%$ of cancer cells are glycolytic [67]. We therefore partition our tumour section so that $60 \%$ of the cells undergo anaerobic glycolysis and the remaining $40 \%$ do not. For details on the derivation of the remaining parameter estimates, see [40]. A summary of the non-dimensional parameter values used in the model is presented in Table 1 (we will refer to this as the base set of parameters). We simulate the model with appropriate nondimensional initial conditions that represent normal tissue levels: $\tilde{H}_{I}^{0}=0.63, \tilde{H}_{E}^{0}=0.63, \tilde{L}_{I}^{0}=1$ and $\tilde{L}_{E}^{0}=1$. We will work with the non-dimensional model hereafter but drop the tildes for notational convenience.

\section{Spatial Distribution of Extracellular Lactate and Hydrogen lons}

Given that there is some uncertainty in the values that we should take for the vessel permeabilities (for example, $\rho_{H l}$ ) - mostly stemming from the uncertainty of the value of $\alpha_{4}$ (i.e. recall that $\rho_{H l}$ (dimensionless) $=\rho_{H l} /\left(\alpha_{4} D_{H}\right)^{1 / 2}$ - we first vary the dimensionless value of $\rho_{H l}$ in our analysis. In particular, we are interested to find if this parameter has any effect on whether the extracellular $\mathrm{pH}$ is less acidic when extracellular lactate is high. Fig. 2 shows how the spatial profile of extracellular $\mathrm{pH}$ at steady state is qualitatively reversed (i.e. from that with an increasing $\mathrm{pH}_{e}$ profile against space to that of a decreasing $\mathrm{pH}_{e}$ profile against space) as $\rho_{H l}$ increases. Note that as $\rho_{H l}$ increases, $\mathrm{pH}_{e}$ slowly increases near the blood vessel and attains a minimum parabolic profile which gradually changes into a monotonically decreasing function as $\rho_{H l}$ further increases. We find that the spatial profile of extracellular lactate, however, remains qualitatively unchanged as $\rho_{H l}$ increases (data not shown).

We show a typical simulation with large $\rho_{H l}$ and $\rho_{L l}\left(=\mathrm{O}\left(10^{3}\right)\right)$ in Fig. 3. Note the "jump" in the intracellular concentration profiles and the activity of the membrane-based transporters 
A
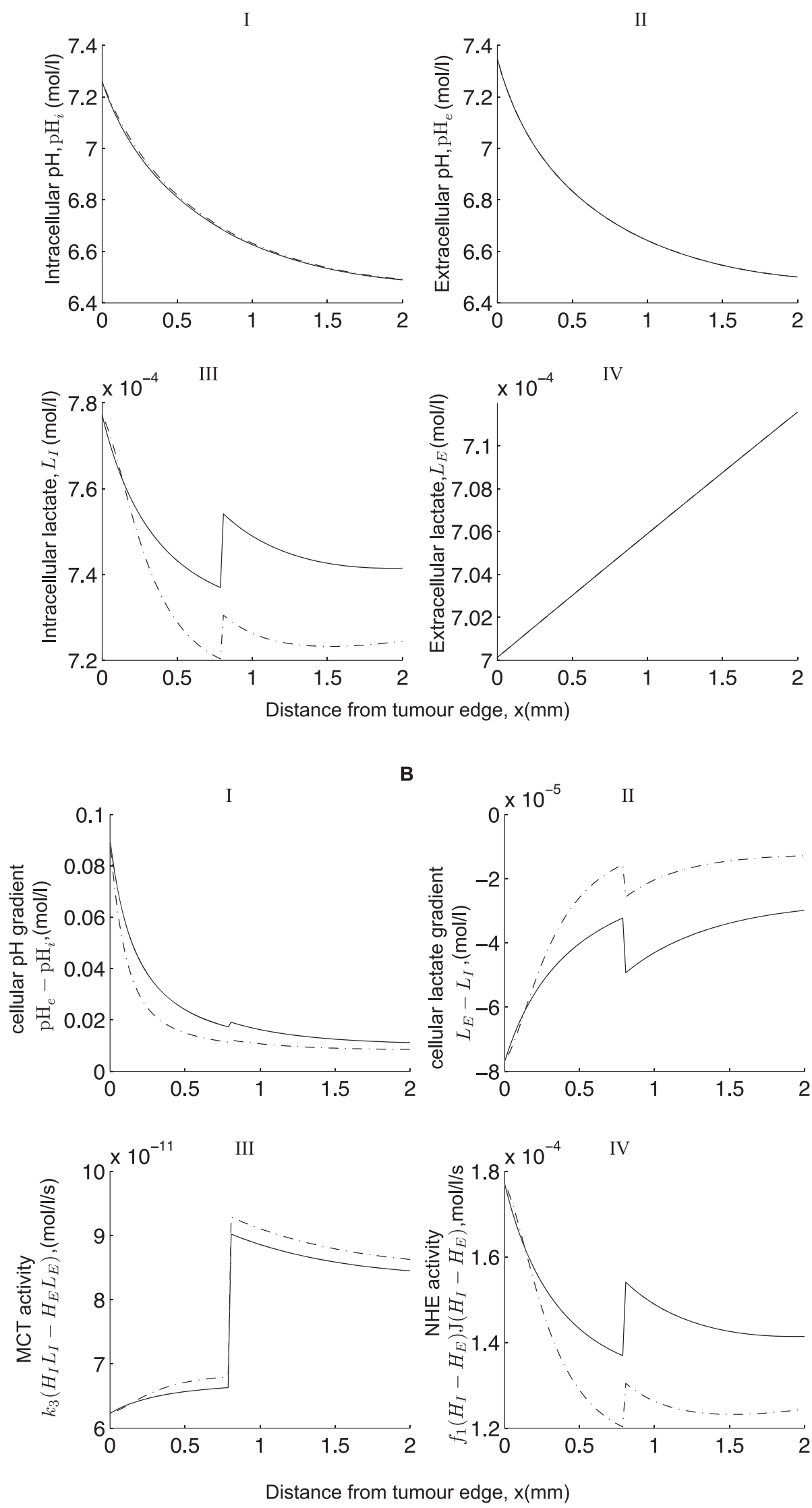
Figure 8. Effect of incorporating a heterogenous intensity of the NHE and MCT in the model. (A) shows the steady state profile of pH and lactate with heterogeneous $(-\cdot-\cdot)$ and homogeneous (-) functions representing the activity of the NHEs and MCTs. (B) Shows hydrogen and lactate gradients and the rates of activity of NHE and MCT. Parameter values are the same as in Fig. 3 but with $k_{4}=1.18, k_{5}=8 \times 10^{-3}, k_{6}=50, f_{2}=0.032, f_{3}=9.9 \times 10^{-5}, f_{4}=10$ representing the heterogenous distribution of NHE and MCT. $f_{1}^{\text {base }}=1.71 \times 10^{4}, k_{3}^{\text {base }}=5.43$.

doi:10.1371/journal.pone.0072020.g008

observed at $x=x^{g}$. This is due to the switch from aerobic metabolism in the $x \leq x^{g}$ region to anaerobic metabolism in the $x>x^{g}$ region where the oxygen levels are low. The extracellular lactate and $\mathrm{pH}$ display no significant observable "jump" in their profile due to the smoothing effect of the extracellular diffusion. The key solution features are as follows: intracellular $\mathrm{pH}$ and extracellular $\mathrm{pH}$ are lower and extracellular lactate is higher in the region further away from the blood vessel (i.e. in the $x>x^{g}$ region) than that in the aerobic region close to the blood vessel. However, intracellular lactate levels increase in the anaerobic region but quickly drop to levels below that found close to the blood vessel. This could be because the NHE activity near the blood vessel is high due to the larger $\mathrm{H}^{+}$-ion transmembrane gradient as a result of an increased removal of extracellular $\mathrm{H}^{+}$-ions into the blood vessel. Consequently, the MCT activity near the blood vessel becomes low because there are less intracellular $\mathrm{H}^{+}$-ions available for extrusion and as a result intracellular lactate levels near the blood vessel become high and decrease as the activity of the NHE decreases (away from the blood vessel).

Note that, a lack of spatial correlation between extracellular acidity $\left(\mathrm{H}^{+}\right.$-ions, recall that $\left.\left[H^{+}\right]=10^{-p H}\right)$ and extracellular lactate is predicted by the model, as shown in Fig. 4. This is in line with the findings of Provent et al. [41] which showed that the glucose-induced increase in extracellular lactate showed no associated decrease in extracellular $\mathrm{pH}$. However, they suggest that the re-distribution of extracellular $\mathrm{H}^{+}$-ions at sites remote from anaerobic lactate production is primarily due to the leakage of $\mathrm{H}^{+}$-ions intracellularly and their subsequent transfer by gap junctions to make them available for extrusion by the NHEs. In contrast, our model predictions suggest that this same result can be observed in the absence of gap junctions, and instead with a reduced permeability of the blood vessels to $\mathrm{H}^{+}$-ions and lactate. In a biological sense, we may interpret our results by suggesting that less-efficient blood vessels, which are indeed frequently found in tumours, can give rise to a contrasting spatial distribution of extracellular $\mathrm{pH}$ and lactate.

\section{Effect of Parameter Variations on the Heterogeneity of the Cellular pH Gradient}

In this section, we study the extent of the reversed cellular $\mathrm{pH}$ gradient in the spatial context and show that, in some cases, the extracellular environment is more acidic than the intracellular for all the cells in the domain or only for non-glycolytic cells or in other cases, no negative cellular $\mathrm{pH}$ gradients are found in any region of the tissue section considered. Our parameter sensitivity analysis of the well-mixed ODE model in [40] shows that the activity of the MCTs (represented by $k_{3}$ ), NHEs $\left(f_{1}\right)$ and other sources of intracellular $\mathrm{H}^{+}$-ions $\left(d_{1}\right)$ play a crucial role in the model behaviour. We now explore whether these parameters are similarly important within this new spatial framework.

Varying the concentration of extracellular lactate in the blood vessel versus that in the tissue. Recall that $L_{\infty l}$ and $L_{\infty}$ denote the concentrations of extracellular lactate in the blood and tissue respectively. Exploring simulation solutions of our model, we find that simply taking lower values of $L_{\infty l}$ causes a reversed cellular $\mathrm{pH}$ gradient across all the cells in the tissue section, as illustrated in Fig. 5. For example, with $L_{\infty l}=0.1$, the cellular $\mathrm{pH}$ gradient is reversed throughout the entire spatial domain considered. This is because, if we take $L_{\infty} l$ to be very small, $L_{E}(0, t)-L_{\infty}$ in the boundary term at $x=0$ is likely to be positive and large, which means that extracellular lactate will leak into the blood stream at a high rate and hence the levels of extracellular lactate throughout the tissue section will be low. This will then facilitate the activity of the MCT (which functions according to the cellular lactate and $\mathrm{H}^{+}$gradient) and consequently will result in a reversed cellular $\mathrm{pH}$ gradient as $\mathrm{H}^{+}$-ions are exported outside the cells along with lactate. We note that in this case, the observed reversed cellular $\mathrm{pH}$ gradients occur at realistic values $\left(\mathrm{pH}_{e} 6.5-7.4\right.$ for the parameters used in Fig. 5) in contrast to our modelling predictions in the well-mixed version of this model, see [40]. As $L_{\infty l}$ increases beyond a threshold value (which we donote by $L_{\infty \ell l}^{*}$ ), the perfusion rate of lactate into the blood decreases, tissue lactate then increases and the MCT activity subsequently decreases. All cells then exhibit a positive cellular $\mathrm{pH}$ gradient. Our model therefore predicts that low levels of lactate found in the blood stream may indirectly cause a reversed cellular $\mathrm{pH}$ gradient in conjunction with an up-regulated tumour activity of the MCT.

Varying the activity of MCTs and other sources of intracellular $\mathbf{H}^{+}$-ions. Fig. 6 shows that the precence of a negative cellular $\mathrm{pH}$ gradient is strongly dependent on both the MCT activity, regulated by the parameter $k_{3}$, and the background production of intracellular $\mathrm{H}^{+}$-ions, $d_{1}$, but also on the concentration of tissue lactate $\left(L_{\infty r}\right)$. Not only is the negative cellular $\mathrm{pH}$ gradient attainable for a larger range of $k_{3}$ and $d_{1}$ values when blood lactate level $\left(L_{\infty} l\right)$ is lowered (compare A with B in Fig. 6), but, when tissue lactate $L_{\infty r}$ is low, a reversed cellular $\mathrm{pH}$ gradient occurs for the base case parameter values (as shown in Table 1, and described in detail in [40]) as indicated by a "diamond" in the figure. We take these base parameters as our most realistic set of values and so it is encouraging for parameter validation purposes that we can reproduce the much observed reversed cellular $\mathrm{pH}$ gradient with this parameter set. Note that we also highlight the region in this $\left(k_{3}, d_{1}\right)$-parameter space in which a reversed cellular $\mathrm{pH}$ gradient is predicted in a non-spatial well-mixed version of this model (below the white curves in Fig. 6, see [40] for full details). The key point here is that, for realistic parameters (including biologically reasonable variations to these values), we are unable to predict a reversed cellular $\mathrm{pH}$ gradient in the well mixed model for our base set of parameters. However, we can within this more realistic new spatial framework when tissue lactate is taken to be sufficiently low. Note also that there is a very small region of $\left(k_{3}, d_{1}\right)$-parameter space where a reversed cellular $\mathrm{pH}$ gradient emerges only for non-glycolytic cells. This occurs in the grey shaded region highlighted in the inserts of Fig. 6.

To interpret the above observations, we note that decreasing $d_{1}$ implies that the amount of $\mathrm{H}^{+}$-ions produced intracellularly is reduced, thereby favouring a more alkaline $\mathrm{pH}_{i}$. Increasing $k_{3}$ then increases the rate of removal of intracellular $\mathrm{H}^{+}$-ions to the extracellular space, which further reduces the $\mathrm{pH}_{i}$ and increases $\mathrm{pH}_{e}$ relative to $\mathrm{pH}_{i}$ and therefore a negative cellular $\mathrm{pH}$ gradient emerges.

Varying the activity of NHEs and other sources of intracellular $\mathbf{H}^{+}$-ions. In contrast, we find that no matter 
A
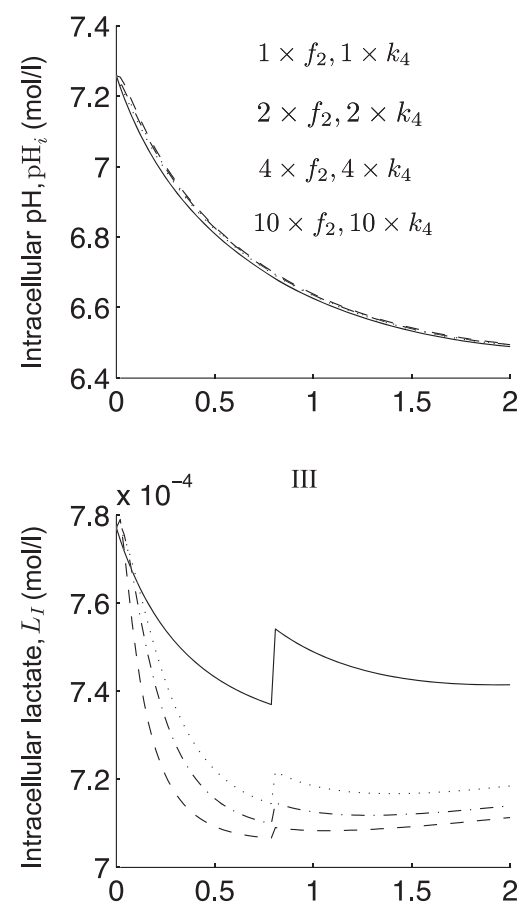

II
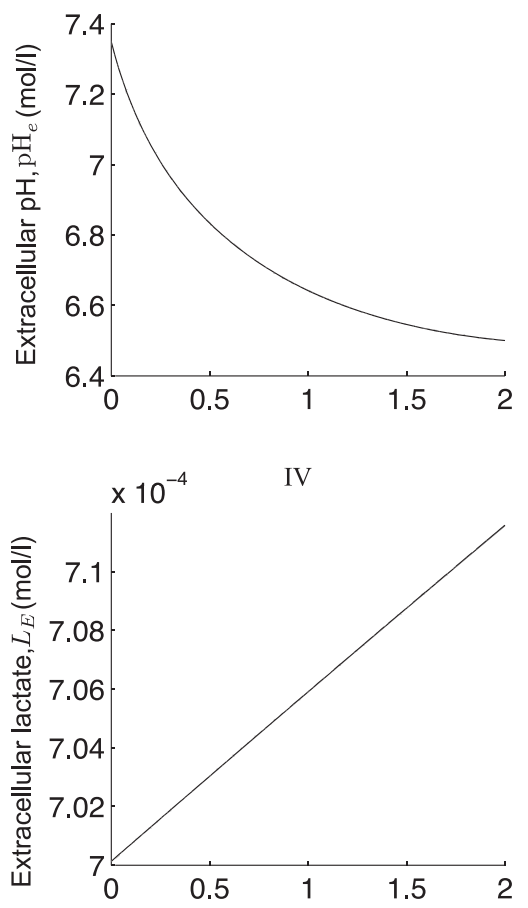

Distance from tumour edge, $x(\mathrm{~mm})$
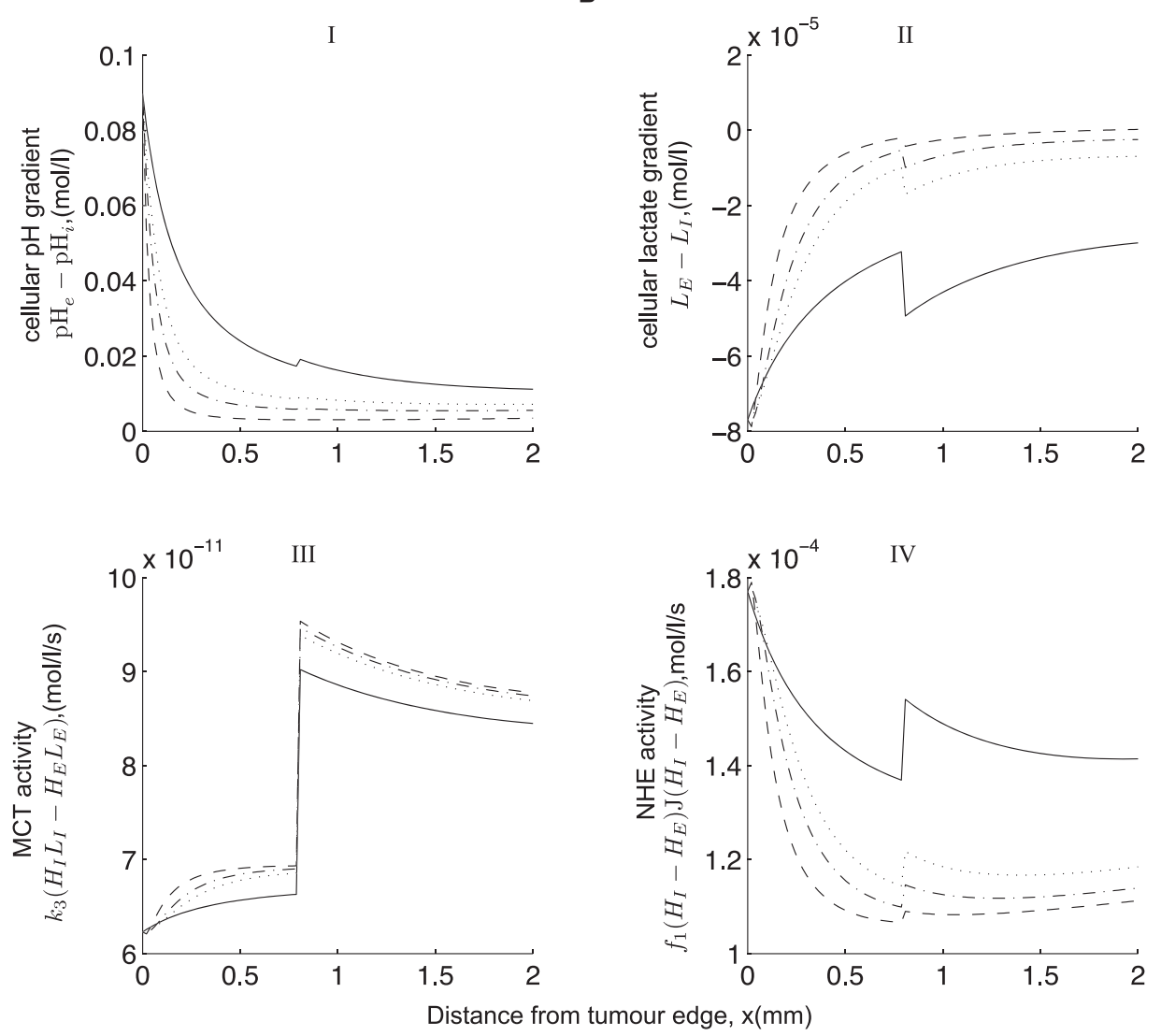
Figure 9. Effect of increasing the magnitude of the maximum rate of activity near the tumour rim of the NHE, $f_{2}$, and MCT, $k_{4}$. It appears that intracellular lactate is the most sensitive metabolite to variations in $f_{2}$ and $k_{4}$. Intracellular pH is also affected, but to a lesser extent. (B) I shows $\mathrm{pH}$ gradient, (B) II lactate gradient, (B) III the MCT activity and (B) IV the NHE activity. Base values: $f_{2}=0.032, k_{3}=1.18$. Remaining parameter values are the same as in the caption to Fig. 3.

doi:10.1371/journal.pone.0072020.g009

how much the rate of activity of the NHEs, regulated by the parameter $f_{1}$, is varied the cellular $\mathrm{pH}$ gradient is reversed throughout the entire tissue section (for all values of $d_{1}$, as long as MCT activity, $k_{3}$, is sufficiently high). Straightforward calculation shows that $H_{E}^{*}$ at steady state does not depend on $f_{1}$ because the rate at which $\mathrm{H}^{+}$-ions enter the extracellular space, in our model, via the membrane-based transporters is equal to the rate of their removal by the blood vessel or their subsequent leakage into the cells. So, an increase in $f_{1}$ does not affect $H_{E}^{*}$ but will decrease $H_{I}^{*}$ via extrusion by the NHE so that $H_{I}^{*}$ quickly becomes smaller than $H_{E}^{*}$ and the cellular $\mathrm{pH}$ gradient becomes reversed. In contrast, for higher values of tissue and blood lactate, the NHE only gives rise to a reversed cellular $\mathrm{pH}$ gradient provided that the level of other sources of $\mathrm{H}^{+}$-ions is small (i.e. $d_{1}$ below a certain threshold). This is because increasing the levels of blood lactate means that extracellular lactate leaks into the blood at a lower rate. This then lowers the activity of the MCT (which functions according to the cellular lactate and $\mathrm{H}^{+}$gradient) and consequently results in less intracellular $\mathrm{H}^{+}$-ions being transported outside the cell along with lactate.

Note that, if we artificially set intracellular and extracellular lactate to be equal, we find no cellular $\mathrm{pH}$ gradient reversal for the range of parameters that we have explored thus far. Crucially, this suggests that lactate plays a pivotal role in determining a reversed cellular $\mathrm{pH}$ gradient, which further motivates its inclusion as separate intracellular and extracellular components in the model.

To summarise, we have shown so far in this study that by allowing diffusion of the extracellular metabolites across the tissue section, we are able to recover a more realistic acidic negative cellular $\mathrm{pH}$ gradient throughout the tissue section-in the aerobic region as well as in the anaerobic region-which the well-mixed ODE model in [40] does not capture.

Our focus in the remainder of this study will be on the impact of a heterogeneous spatial distribution of NHEs and MCTs on the extent of the spatial cellular $\mathrm{pH}$ gradient reversal and on the spatial correlation of extracellular lactate and low $\mathrm{pH}_{e}$.

\section{Heterogeneous Distribution of MCT and NHE}

So far, we have assumed that the MCTs and NHEs are homogeneously distributed on cells throughout the spatial domain. However, recent experiments carried out by Grillon et al. [42] on C6 rat gliomas reveal that the relative intensity of NHE peaks at a distance of $0.33 \pm 0.027 \mathrm{~mm}$ away from the tumour edge and that the intensity of MCT is also up-regulated at $1.05 \pm 0.14 \mathrm{~mm}$ from the edge of the tumour. The authors represent this spatial organisation of the transporters across the tumour rim graphically as shown in Fig. 7. With this in mind, we incorporate the following functions for the heterogenous expression of the NHE $\left(f_{1}\right)$ and the $\operatorname{MCT}\left(k_{3}\right)$, namely.

$$
\begin{gathered}
f_{1}=\left(1+\frac{f_{2} x}{f_{3}+f_{4} x^{2}}\right) f_{1}^{\text {base }} \\
k_{3}=\left(1+\frac{k_{4}}{k_{5}+k_{6} x^{2}}\right) k_{3}^{\text {base }}
\end{gathered}
$$

where, $f_{i}(i \in 2,3,4), k_{j}(j \in 4,5,6)$ are chosen to best fit the curves shown in Fig. 7 , and $f_{1}^{\text {base }}, k_{3}^{\text {base }}$ denote the base parameter values as presented in Table 1. It turns out, however, that incorporating these functions in our model has no qualitative effect on the $\mathrm{pH}$ and lactate profiles for the parameter values considered (see Fig. 8). Quantitatively, there is relatively little change to the levels of $\mathrm{pH}_{i}$ and no observable change to $\mathrm{pH}_{e}$ and $L_{E}$. However, there is a noticeable change in the levels of intracellular lactate which is due to the variations in MCT activity. That is, intracellular lactate levels increase near the tumour edge due to a higher NHE activity there (compared to MCT activity) which leaves less intracellular $\mathrm{H}^{+}$to bind with lactate for extrusion via the MCT and so intracellular lactate builds up. But as the NHE activity then drops further into the tumour (see Fig. 7), intracellular lactate begins to fall due to an increased MCT activity. However, this change in the NHE activity only appears to cause a small change in intracellular pH (see Fig. 8B(IV)). Therefore, it appears that the variations in MCT activity is the dominating factor here.

We show in Fig. 9 that variations in the parameters that represent the maximum rate of activity of the NHE transporter, $f_{2}$, and the MCT transporter, $k_{4}$, results in a qualitatively similar profile to that seen in Fig. 8. We see, however, a slight change in the qualitative profiles of intracellular lactate and intracellular $\mathrm{pH}$ near the blood vessel (near $x=0$ ). This is attributed to a sharp increase in the NHE activity and a slight dip in the MCT activity which results in a sharp increase in intracellular lactate levels there (see Fig. 9, III and IV). So in conclusion, our model suggests that an increased expression of the MCT and NHE near the tumour edge can affect the intracellular levels of lactate (the key effects being dominated by the MCT), but the effect on intracellular $\mathrm{pH}$ is much lower.

\section{The Inclusion of Intercellular Gap Junctions for $\mathrm{H}^{+}$-ions}

It has been suggested that a lack of spatial correlation between an increase in extracellular lactate and a decrease in extracellular $\mathrm{pH}$ exists in some tumours because protons, which are exported extracellularly along with lactate in hypoxic regions, re-enter the cells indirectly via the $\mathrm{HCO}_{3}^{-} / \mathrm{Cl}^{-}$exchanger or simply leak back into the cell and then are transported cell-to-cell via gap junctions to make protons available for the NHE exchanger [41]. In this section, we examine whether incorporating $\mathrm{H}^{+}$-ion intercellular gap junctions into our model has any effect on whether high extracellular lactate is correlated with a decrease in extracellular $\mathrm{pH}$.

We now introduce the following gap junction intercellular communication term,

$$
g_{j}=k\left(H_{I}(j+1)-2 H_{I}(j)+H_{I}(j-1)\right),
$$

into the spatially discretised form of equation (1), where $j$ denotes the cell at spatial position $j, H_{I}(j)$ is the intracellular $\mathrm{H}^{+}$-ion concentration in that cell and $k$ represents the rate of gap junction transfer of $\mathrm{H}^{+}$between cells. Due to the lack of available data, we vary the magnitude of $k$ and illustrate the effect on the spatial profile of $\mathrm{pH}$ and lactate in Fig. 10.

We observe that as $k$ increases, the intracellular $\mathrm{pH}$ decreases in the aerobic region $\left(V \geq V^{g}\right)$ and increases in the glycolytic region $\left(V<V^{g}\right)$ due to the intracellular $\mathrm{H}^{+}$-ions being transferred via gap 
A
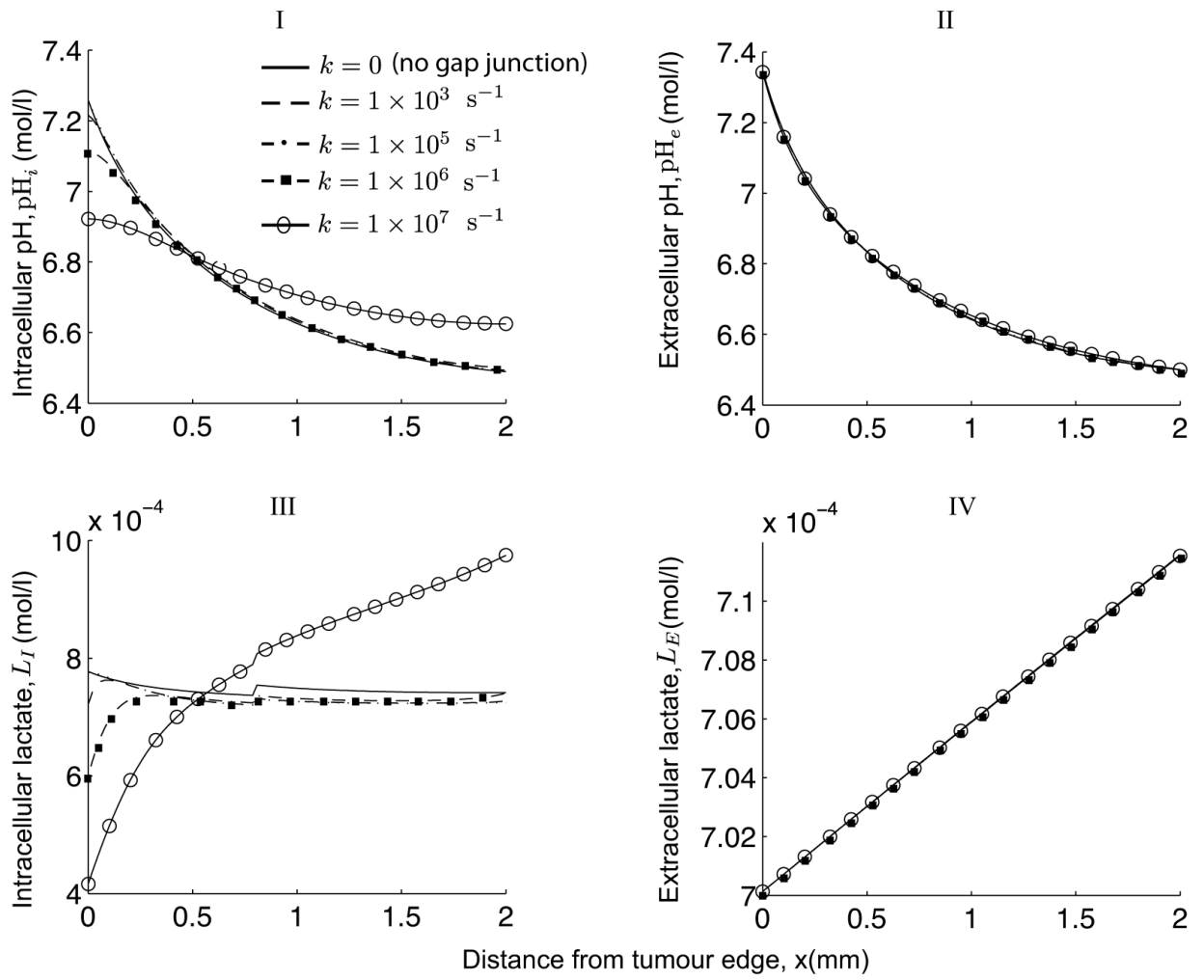

B
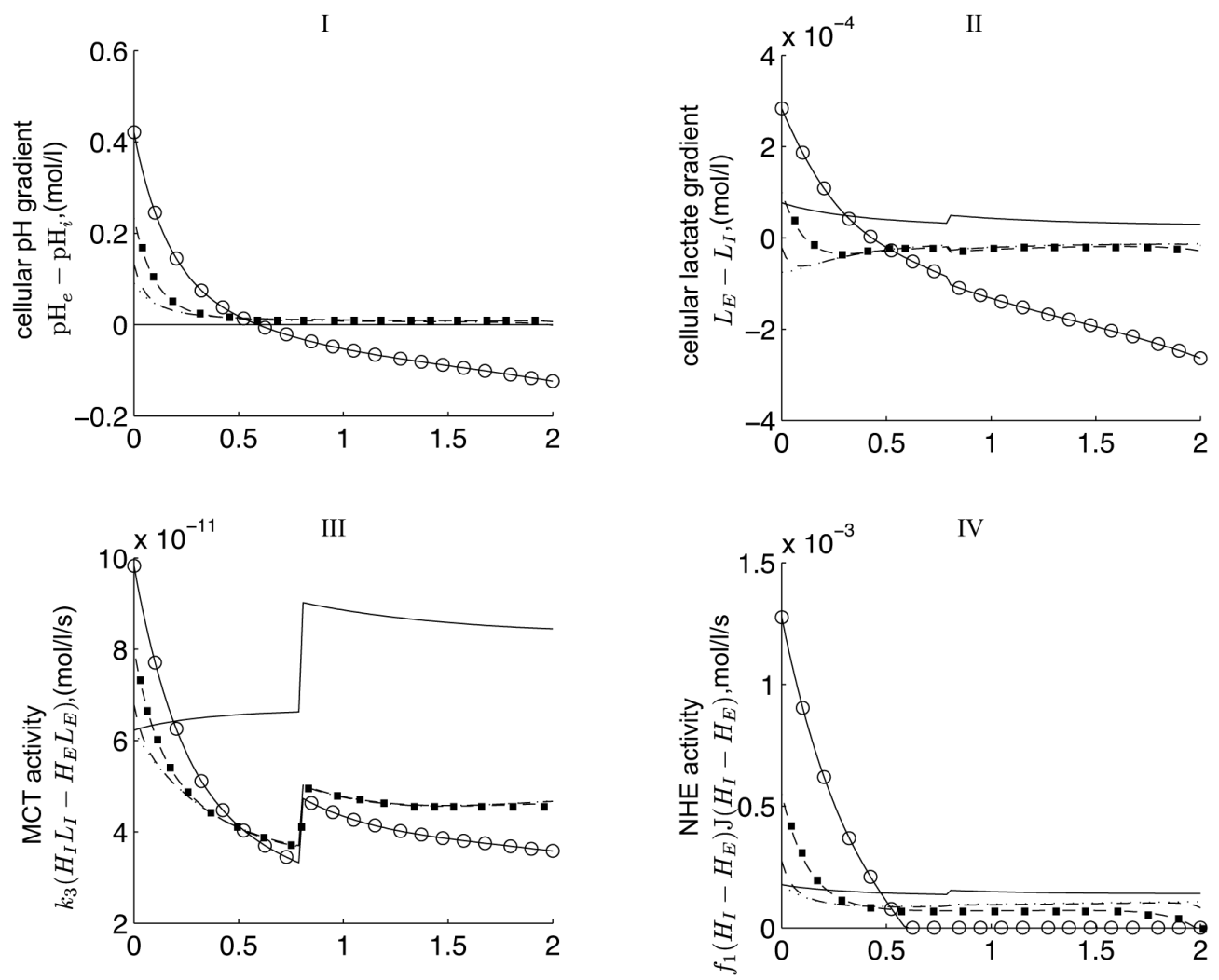

Distance from tumour edge, $x(\mathrm{~mm})$ 
Figure 10. Effect of varying the rate of $\mathbf{H}^{+}$transfer between cells, $k$, on $\mathbf{p H}$ and lactate profiles. Plots showing how the spatial profile of: (A) I $\mathrm{pH}_{i}^{*}$ and (A) III $L_{I}^{*}$ are affected as the rate of $\mathrm{H}^{+}$transfer between cells, $k$, is varied and how little (A) II $\mathrm{pH}_{e}^{*}$ and (A) IV $L_{E}^{*}$ profiles change in comparison. (B) I shows pH gradient, (B) II lactate gradient, (B) III the MCT activity and (B) IV the NHE activity. Parameter values are the same as in the caption to Fig. 3.

doi:10.1371/journal.pone.0072020.g010

junctions from the glycolytic region (where they are produced in excess) to the aerobic region. As a result, extracellular $\mathrm{pH}$ increases in the $V<V^{g}$ region (due to there being less intracellular $\mathrm{H}^{+}$-ions to be pumped outside the cell via the NHE or MCT) and decreases in the $V \geq V^{g}$ region (due to there being more intracellular $\mathrm{H}^{+}$-ions being pumped outside the cell). Extracellular lactate, however, remains largely insensitive and is essentially constant and this is attributed to its leakage into the surrounding tissue. However, we do see a slight increase in extracelluar lactate as the distance into the tissue section increases (see A IV) and note that the concentrations of extracellular $\mathrm{H}^{+}$and lactate then become spatially correlated (i.e. high $\left[\mathrm{H}^{+}\right]_{e}\left(\right.$ low $\mathrm{pH}_{e}$ ) corresponding to high $\mathrm{L}_{E}$, see (A) II with (A) IV in Fig. 10). Admittedly, this is only a very weak correlation but is contrary to the hypothesis provided in $[41,42]$ which associates the activity of the $\mathrm{H}^{+}$ intercellular gap junctions with the lack of correlation between low $\mathrm{pH}_{e}$ and high extracellular lactate. Also, intracellular lactate decreases in the $V \geq V^{g}$ region (due to there being more intracellular $\mathrm{H}^{+}$-ions being pumped outside the cell along with lactate via the MCTs) and increases in the $V<V^{g}$ region (due to there being less intracellular $\mathrm{H}^{+}$-ions pumped outside the cell via the MCTs).

Furthermore, a reversed cellular $\mathrm{pH}$ gradient is observed in the glycolytic region, which is due to the intracellular $\mathrm{H}^{+}$-ions being transferred via the gap junctions from the glycolytic region (where they are produced in excess) to the aerobic region and thus lowering the levels of intracellular $\mathrm{H}^{+}$-ions in the glycolytic region and raising it in the aerobic region. Note that a sufficiently high value of gap junction transfer is required, 400 times quicker than the MCT and $10^{6}$ times quicker than the NHE activity, to see a significant effect on the cellular metabolite gradients (see Fig. 10).

\section{Discussion and Conclusions}

One of the key questions that we wanted to answer in this work is can a spatial extension of our $\mathrm{pH}$ regulation model in [40] facilitate reversed cellular $\mathrm{pH}$ gradients such as that observed in many human tumours. The model in [40] is based on a well mixed framework and only predicts reversed cellular $\mathrm{pH}$ gradients for unrealistic $\mathrm{pH}$ values. We show in this article, however, that a simple spatial extension of this model, with no additional transporter or buffering terms, can predict reversed cellular $\mathrm{pH}$ gradients for much more realistic $\mathrm{pH}$ values, suggesting a potential critical role for the $\mathrm{Na}^{+} / \mathrm{H}^{+}$and lactate $/ \mathrm{H}^{+}$transporters in the maintenance of such features. The second key question is whether lactate and $\mathrm{H}^{+}$-ions are spatially correlated. In other words, are their concentrations qualitatively similar throughout the tumour? One may intuitively assume that since lactate and $\mathrm{H}^{+}$are produced together via glycolysis then the extracellular concentrations may then marry and, indeed, the diagnostic significance of high lactate has been implicated in numerous studies showing an association between high lactate and the incidence of metastasis $[28,29]$. However, a recent study by Parkins et al [8] show that, under conditions of severe cell stress, the $\mathrm{pH}_{e}$ declines in the absence of a corresponding accumulation of extracellular lactate and we indeed confirm such features in our model, highlighting that lactate should not be used as a standard indicator for extracellular acidity in tumours.
We have demonstrated in this spatial model that areas with high extracellular lactate can coincide with high extracellular $\mathrm{H}^{+}$-ion concentrations. However, when the rate of removal of $\mathrm{H}^{+}$-ions and lactate by blood vessels is reduced, lower extracellular lactate concentrations can exist where extracellular $\mathrm{H}^{+}$-ion concentrations are at their highest level. This result suggests a role for blood vessel perfusion rates in determining the spatial correlation of extracellular $\mathrm{pH}$ and lactate. Tumour blood vessels are chaotic and an order of magnitude leakier than normal vessels [68]. This is known to result in an increased interstitial fluid pressure inside tumours which can hamper the uptake of therapeutic agents [10]. Recently, Martin et al. [69] extended the acid-mediated tumour invasion model [36] by including the effect of vessel permeability on the acid gradient from the centre of the tumour to the normal tissue. They find that leaky vasculature (those with high vessel permeability) can lead to an overall acidification of the normal tissue further from the tumour boundary, and our present study agrees with this result (that is, if we take non-glycolytic cells to be representatives of normal cells).

The motivation of our work is to also determine the relative importance and inter-relationships between some of the main parameters involved in the spatial reversed cellular $\mathrm{pH}$ gradient, concentrating in particular on the influence of changes in tissue and blood lactate levels, background production of $\mathrm{H}^{+}$-ions and the activity of the MCTs and NHEs. We find that simply taking lower values of blood lactate levels gives a reversed cellular $\mathrm{pH}$ gradient throughout the spatial domain independent of the levels of tissue lactate. This is because, with lower blood lactate values, extracellular lactate leaks into the blood vessel until the level of lactate in the tissue equates that in the blood vessel. Hence, the lower the blood lactate level is, the lower the tissue extracellular lactate becomes, which in turn drives the MCTs to export lactate and $\mathrm{H}^{+}$-ions outside the cell at a higher rate due to the larger lactate gradient. This suggests that low levels of lactate found in the blood stream may indirectly cause a reversed cellular $\mathrm{pH}$ gradient in conjunction with an up-regulated tumour activity of the MCT. Likewise, we have found the existence of a reversed cellular $\mathrm{pH}$ gradient to be strongly dependent on the combined activity of the MCTs and background sources of $\mathrm{H}^{+}$-ion. In addition, we have found the cellular $\mathrm{pH}$ gradient to be always reversed no matter how high or low the NHE activity is, provided that the level of background sources of $\mathrm{H}^{+}$-ions is below a certain threshold. The ability of extracellular $\mathrm{H}^{+}$-ions to leak into the neighbouring blood vessel and to diffuse across the tissue from higher to lower concentrations means that the reversed cellular $\mathrm{pH}$ gradient occurs at more realistic values and is less alkaline $\left(\mathrm{pH}_{e}=6.5-7.4\right)$ than that observed in the well-mixed system we studied in [40] $\left(\mathrm{pH}_{e}=7.5-9.5\right)$. In terms of the significance of our results to anti-cancer therapy, we propose that decreasing intracellular $\mathrm{H}^{+}$production rate and the activity of the MCT would lead to a normal cellular $\mathrm{pH}$ gradient and potentially aid in the uptake of some chemotherapeutic drugs.

Recent experiments carried out by Grillon et al. [42] on C6 rat gliomas reveal that the relative intensity of NHEs peak at a distance of $0.33 \pm 0.027 \mathrm{~mm}$ away from the edge of the tumour and that the intensity of MCTs is also up-regulated at $1.05 \pm 0.14 \mathrm{~mm}$ from the edge. The inclusion of heterogeneous expressions of the NHEs and the MCTs as in [42] has no 
qualitative effect on the model behaviour, but a considerable increase in their rate of activity can have a slight change on intracellular levels of lactate and intracellular $\mathrm{pH}$. Quantitatively, this causes a significant difference to the intracellular levels of lactate which is attributed to the activity of the MCT. However, there is a relatively small effect on the intracellular $\mathrm{pH}$. Based on our model, we therefore suggest that an up-regulated expression of NHE and MCT in the growing outer part of a tumour can give rise to a higher intracellular $\mathrm{pH}$ (which is known to aid tumour cell migration [70] and proliferation [71]) but may not result in a reversed cellular $\mathrm{pH}$ gradient or a redistribution of protons away from the glycolytic source. On the other hand, including intercellular gap junction communication can give rise to a reversed cellular $\mathrm{pH}$ gradient. Note that in order for this to

\section{References}

1. Martinez-Zaguilan R, Seftor EA, Seftor RE, Chu YW, Gillies RJ, et al. (1996) Acidic $\mathrm{pH}$ enhances the invasive behaviour of human melanoma cells. Clin Exp Metastas 14: 176-186.

2. Nyberg P, Salo T, Kalluri R (2008) Tumor microenvironment and angiogenesis. Front Biosci 1: 6537-6553.

3. Brown JM (2002) Tumor microenvironment and the response to anticancer therapy (review). Cancer Biol Ther 1: 453-458.

4. Henning T, Krausb M, Brischweina M, Ottoa AM, Wolfa B (2004) Relevance of tumor microenvi ronment for progression, therapy and drug development (review). Anti-Cancer Drugs 15: 7-14.

5. Webb BA, Chimenti M, Jacobson MP, Barber DL (2011) Dysregulated pH: a perfect storm for cancer progression. Nat Rev Cancer 11: 671-700.

6. Boron WF (1986) Intracellular $\mathrm{pH}$ regulation in epithelial cells. Annu Rev Physiol 48: 377-388.

7. Gillies RJ, Raghunand N, Karczmar GS, Bhujwalla ZM (2002) MRI of the tumor microenviron ment. J Magn Reson Imaging 16: 430-450.

8. Parkins CS, Stratford MRL, Dennis MF, Stubbs M, Chaplin DJ (1997) The relationship between extracellular lactate and tumour $\mathrm{pH}$ in a murine tumour model of ischaemia-reperfusion. Brit J Cancer 75: 319-323.

9. Pouysségur J, Dayan F, Mazure N (2006) Hypoxia signalling in cancer and approaches to enforce tumour regression. Nature 441: 437-443.

10. Raghunand N, Gatenby RA, Gillies RJ (2003) Microenvironmental and cellular consequences of altered blood ow in tumours. Br J Radiol 76: S11-S22.

11. Rofstad EK, Mathiesen B, Kindem K, Galappathi K (2006) Acidic extracellular $\mathrm{pH}$ promotes experimental metastasis of human melanoma cells in athymic nude mice. Cancer Res 66: 6699-6707.

12. Tannock IF, Rotin D (1989) Acid pH in tumours and its potenial for therapeutic exploitation. Cancer Res 49: 4373-4384.

13. Wachsberger PR, Landry J, Storck C (1997) Mammalian cells adapted to growth at $\mathrm{pH} 6.7$ have eleveted HSP27 levels and are resistant to cisplatin. Int J Hyperther 13: 251-255.

14. Pouysségur J, Franchi A, L'Akmain G, Paris S (1985) Cytoplasmic pH, a key determinant of growth factor-induced DNA synthesis in quiescent fibroblasts. Federation of European Biochemical Societies 190: 115-119.

15. Putney LK, Barber DL (2003) Na-H exchange-dependent increase in intracellular $\mathrm{pH}$ times G2/M entry and transition. J Biol Chem 278: 446454469.

16. Lagadic-Gossmann D, Huc L, Lecureur V (2004) Alterations of intracellular pH homeostasis in apoptosis: origins and roles. Cell Death Differ 11: 953-961.

17. Matsuyama S, Llopis J, Deveraux QL, Tsien RY, Reed JC (2000) Changes in intramitochondrial and cytosolic $\mathrm{pH}$ : early events that modulate caspase activation during apoptosis. Nat Cell Biol 2: 318-325.

18. Stock C, Gassner B, Hauck CR, Arnold H, Mally S, et al. (2005) Migration of human melanoma cells depends on extracellular $\mathrm{pH}$ and $\mathrm{Na}+/ \mathrm{H}+$ exchange. J Physiol 567: 225-238.

19. Warburg O, Wind F, Negelein E (1926) The metabolism of tumours in the body. J Gen Physiol 8: 519-530.

20. Berg JM, Tymoczko JL, Stryer L (2003) Biochemistry. W. H. Freeman, New York, 5th edition.

21. Griffths JR (1991) Are cancer cells acidic? Br J Cancer 3: 425-427.

22. Romero MF (2004) In the beginning, there was the cell: cellular homeostasis. Adv Physiol Educ 28: 135-138.

23. Fitzgerald RC, Omary MB, Triadafilopoulos G (1997) Acid modulation of HT29 cell growth and differentiation. J Cell Sci 110: 663-671.

24. Humez S, Monet M, Coppenolle FV, Delcourt P, Prevarskaya N (2003) The role of intracellular $\mathrm{pH}$ in cell growth arrest induced by ATP. Am J Physiol Cell Physiol 287: C1733-C1746.

25. Boron WF (1985) Intracellular pH-regulating mechanisms for the squid axons: Relation between the external $\mathrm{Na}+$ and $\mathrm{HCO}_{3}^{-}$dependences. J Gen Physiol 85: 325-345. happen, intercellular gap $\mathrm{H}^{+}$-ion transfer needs to be much more rapid compared to the other transporter processes in the model (i.e. 400 times quicker than the MCT and $10^{6}$ times quicker than the NHE activity). This results in intracellular $\mathrm{H}^{+}$-ions being transferred from the glycolytic region (where they are produced in excess) to the aerobic region and thus lowering the levels of intracellular $\mathrm{H}^{+}$-ions in the glycolytic region and raising it in the aerobic region.

\section{Author Contributions}

Conceived and designed the experiments: SW. Analyzed the data: SW MA. Wrote the paper: SW MA. Performed mathematical modelling: SW MA.

26. Mackenzie CG, Mackenzie JB, Beck P (1961) The effect of pH on growth, protein synthesis, and lipid-rich particles of cultured mammalian cells. J Biophys Biochem Cytol 9: 141-156.

27. Aronson PS (1985) Kinetic properties of the plasma membrane Na+-H+ exchanger. Ann Rev Physiol 47: 545-560.

28. Walenta S, Wetterling M, Lehrke M, Schwickert G, Sundfør K, et al. (2000) High lactate levels predict likelihood of metastasis, tumor recurrence, and restricted patient survival in human cervical cancers. Cancer Res 16: 916-921.

29. Schwickert G, Walenta S, Sundfør K, Rofstad EK, Mueller-Kliesera W (1995) Correlation of high lactate levels in human cervical cancer with incidence of metastasis. Cancer Res 55: 4757-4759.

30. Ouennet V, Yaromina A, Zips D, Rosner A, Walenta S, et al. (2006) Tumor lactate content predicts for response to fractionated irradiation of human squamous cell carcinomas in nude mice. Radiother Oncol 81: 130-135.

31. Cardone RA, Casavola V, Reshkin SJ (2005) The role of distributed pH dynamics and the $\mathrm{Na}+\mathrm{H}+$ exchanger in metastasis. Nat Rev Cancer 5: 786795 .

32. Bunimovich-Mendrazitsky S, Byrne H, Stone K (2008) Mathematical model of pulsed immunotherapy for superficial bladder cancer. Bull Math Biol 70: 20552076 .

33. Chaplain MAJ, McDougall SR, Anderson ARA (2006) Mathematical modeling of tumour-induced angiogenesis. Annu Rev Biomed Eng 8: 233-257.

34. Gerisch A, Chaplain MAJ (2008) Mathematical modelling of cancer cell invasion of tissue: Local and non-local models and the effect of adhesion. J Theor Biol 250: $684-704$.

35. Smallbone K, Gavaghan DJ, Gatenby RA, Maini PK (2005) The role of acidity in solid tumour growth and invasion. J Theor Biol 235: 476-484.

36. Gatenby RA, Gawlinski ET (1996) A reaction diffusion model of cancer invasion. Cancer Res 56: 5745-5753.

37. Neville AA (2003) Biomedical Modelling incorporating growth. Ph.D. thesis, University of Nottingham.

38. Webb SD, Sherratt JA, Fish RG (1999) Alterations in proteolytic activity at low $\mathrm{pH}$ and its association with invasion: A theoretical model. Clin Exp Metastas 17: 397-407.

39. Webb SD, Sherratt JA, Fish RG (1999) Mathematical modelling of tumour acidity: Regulation of intracellular pH. J Theor Biol 196: 237-250.

40. Al-Husari M, Webb SD (2013) Regulation of tumour intracellular pH: A mathematical model examining the interplay between $\mathrm{H}+$ and lactate. $\mathrm{J}$ Theor Biol 322: 58-71.

41. Provent P, Benito M, Hiba B, Farion R, López-Larrubia P, et al. (2007) Serial In vivo spectro scopic nuclear magnetic resonance imaging of lactate and extracellular $\mathrm{pH}$ in rat gilomas shows redistribution of protons away from sites of glycolysis. Cancer Res 67: 7638-7645.

42. Grillon E, Farion R, Fablet K, Waard MD, Tse CM, et al. (2011) The spatial organization of proton and lactate transport in a rat brain tumor. PloS ONE 6: $1-9$.

43. Halestrap AP, Meredith D (2004) The SLC16 gene family-from monocarboxylate transporters (MCTs) to aromatic amino acid transporters and beyond. Pug Arch Eur J Phy 447: 619-628.

44. Boyer MJ, Tannock IF (1992) Regulation of intracellular $\mathrm{pH}$ in tumour cell lines: Inuence of microenvironmental conditions. Cancer Res 52: 4441-4447.

45. Vinnakota KC, Beard DA (2011) Kinetic analysis and design of experiments to identify the catalytic mechanism of the monocarboxylate transporter isoforms 4 and 1. Biophys J 100: 369-380.

46. Aubert A, Costalat R, Magistretti PJ, Pellerin L (2005) Brain lactate kinetics: modeling evidence for neural lactate uptake upon activation. PNAS 102: 1644816453.

47. Lawrence E (1989) A Guide to Modern Biology: Genetics, Cells and Systems. Addison-Wesley Longman Ltd.

48. McDermott JC, Bonen A (1993) Lactate transport by skeletal muscle sarcolemmal vesicles. Mol Cell Biochem 122: 113-121. 
49. Swietach P, Vaughan-Jones RD, Harris AL (2007) Regulation of tumor $\mathrm{pH}$ and the role of carbonic anhydrase 9. Cancer Metast Rev 26: 299-310.

50. Kaminskas E (1978) The pH-dependence of sugar-transport and glycolysis in cultured ehrlich ascites-tumour cells. Biochem J 174: 453-459.

51. Casciari JJ, Sotirchos SV, Sutherland RM (1992) Variations in tumour cell growth rates and metabolism with oxygen concentrations, glucose concentration, and extracellular pH. J Cell Physiol 151: 386-394.

52. Hochachka PW, Mommsen TP (1983) Protons and anaerobiosis. 587 Science 219: 1391-1397.

53. Vaupel P, Kallinowski F, Okunieff P (1989) Blood flow, oxygen and nutrient supply, and metabolic microenvironment of human tumors. Cancer Res 49: 6449-6465.

54. Lodish H, Berk A, Zipursky SL, Matsudaira P, Baltimore D, et al. (2008) Molecular Cell Biology. W. H. freeman, New York, 4th edition.

55. Brooks GA (1986) Lactate production under fully aerobic conditions: the lactate shuttle during rest and exercise. Fed Proc 45.

56. Sauer LA, Stayman JW, Dauchy RT (1982) Amino acid, glucose, and lactic acid utilization in vivo by rat tumors. Cancer Res 42: 4090-4097.

57. Schumer W (1978) Cell metabolism and lactate. In: Bossart H, Perret C, editors, Lactate in Acute Conditions International Symposium. Basel, 1-9.

58. Bertuzzi A, Fasano A, Gandolfi A, Sinisgalli C (2010) Necrotic core in EMT6/ Ro tumor spheroids: Is it caused by an ATP deficit? J Theor Biol 262: 142-150.

59. Lide DR, editor (1994) Handbook of Chemistry and Physics. CRC Press, 74 edition.

60. Zhang X, Li CG, Ye CH, Liu ML (2001) Determination of molecular selfdiffusion coefficient using multiple spin-echo NMR spectroscopy with removal of convection and background gradient artifacts. Anal Chem 73: 3528-3534.
61. Crone C, Levitt DG (1984) Capillary permeability to small solutes. In: Renkin EM, Michel CC, editors, Handbook of Physiology: A critical, comprehensive presentation of physiological knowledge and concepts, Bethesda, ML: American Physiological Society, volume IV, chapter 2: The Cardiovascular System. 414 and $434-437$.

62. Nichol A, Bailey M, Egi M, Pettila V, French C, et al. (2011) Dynamic lactate indices as predictors of outcome in critically ill patients. Critical Care 15.

63. Boldt J, Kumle B, Suttner S, Haisch G (2001) Point-of-care (POC) testing of lactate in the intensive care patient. Acta Anaesthesiol Scand 45: 194-199.

64. Porth CM (1995) Pathophysiology: concepts of altered health states. Lippincott company, Penn sylvania, 4th edition.

65. Gatenby RA, Gillies RJ (2004) Why do cancers have high aerobic glycolysis? Nature Rev 4: 891-899.

66. Gatenby RA, Gillies RJ (2007) Glycolysis in cancer: a potential target for therapy. Int J Biochem Cell B 39: 1358-1366.

67. Dakubo GD (2010) Mitochondrial Genetics and Cancer. Springer.

68. McDonald DM, Baluk P (2002) Significance of blood vessel leakiness in cancer. Cancer Res 62: 5381-5385.

69. Martin NK, Gaffney EA, Gatenby RA, Maini PK (2010) Leaky vessels as a potential source of stromal acidification in tumours. J Theor Biol 267: 454-460.

70. Martin C, Pedersen SF, Schwab A, Stock C (2011) Intracellular pH gradients in migrating cells. Am J Physiol Cell Physiol 300: C490-C495.

71. Gillies RJ, Martinez-Zaguilan R, Peterson E, Perona R (1992) Role of intracellular $\mathrm{pH}$ in mammalian cell proliferation. Cell Physiol Biochem 2: 159-79. 